\title{
Rydberg spectra of singlet metastable states of $\mathrm{O}_{2}$
}

C. M. Western, School of Chemistry, University of Bristol, Cantock's Close, Bristol BS8 1TS, UK

J-P. Booth, A. Chatterjee, Laboratoire de Physique des Plasmas, CNRS, Ecole Polytechnique, Sorbonne Université, Univ Paris-Sud, France

N. de Oliveira, Synchrotron Soleil, Orme des Merisiers, St. Aubin, BP 48, 91192 Gif sur Yvette Cedex, France Abstract

Updated analyses of several singlet Rydberg states of $\mathrm{O}_{2}$ via spectra involving excitation from the metastable $\mathrm{a}^{1} \Delta_{\mathrm{g}}$ and $\mathrm{b}^{1} \Sigma_{\mathrm{g}}{ }^{+}$states are presented. The high quality FT-VUV spectra available from the DESIRS beamline at the SOLEIL synchrotron gives significantly improved spectra compared to previous work. The Rydberg states analysed include $3 p \pi^{1} \Sigma_{\mathrm{u}}^{+} \mathrm{v}=0-4,3 p \sigma^{1} \Pi_{\mathrm{u}}$ $\mathrm{v}=0-2,3 p \pi^{1} \Delta_{\mathrm{u}} \mathrm{v}=0-2,4 \mathrm{p} \pi^{1} \Sigma_{\mathrm{u}}{ }^{+} \mathrm{v}=0-1,4 \mathrm{p} \sigma^{1} \Pi_{\mathrm{u}} \mathrm{v}=0$ and $4 \mathrm{p} \pi^{1} \Delta_{\mathrm{u}} \mathrm{v}=0$. This is complemented by high quality ab initio calculations on the ${ }^{1} \Sigma_{\mathrm{u}}{ }^{+}$and ${ }^{1} \Delta_{\mathrm{u}}$ Rydberg states to determine the transition moments providing the first quantitative cross sections for Rydberg $-b^{1} \Sigma_{g}{ }^{+}$transitions. These are validated against the experimental data. The results suggest the most promising candidate for determining $\mathrm{b}^{1} \Sigma_{\mathrm{g}}{ }^{+}$number density is likely to be the 1-0 band of the $4 \mathrm{p} \pi^{1} \Sigma_{\mathrm{u}}{ }^{+}-\mathrm{b}^{1} \Sigma_{\mathrm{g}}{ }^{+}$ transition at $131.3 \mathrm{~nm}$.

Keywords: Spectroscopy; Rydberg States; Oxygen; Metastable states; Vacuum Ultraviolet

Word Count: 10450 


\section{Introduction}

The oxygen molecule is rather unusual for a stable diatomic in that it possesses lowlying metastable states, the $\mathrm{a}^{1} \Delta_{\mathrm{g}}$ state at $0.98 \mathrm{eV}$ and the $\mathrm{b}^{1} \Sigma_{\mathrm{g}}{ }^{+}$state at $1.63 \mathrm{eV}$ above the ground state. In low-pressure plasmas, in which the typical electron temperature is of the order of a few eV, these states can be significantly populated, and may therefore have an impact on the kinetics of both neutral and charged particles. For example, in a pure oxygen discharge the $\mathrm{O}_{2}$ $\mathrm{a}^{1} \Delta_{\mathrm{g}}$ state is known to play an important role in the destruction of $\mathrm{O}^{-}$negative ions through associative detachment reactions [1-3], strongly affecting the plasma electrical characteristics[4-8]. Furthermore, it can react with $\mathrm{O}_{3}$ [9] to produce $\mathrm{O}^{3} \mathrm{P}$ atoms.

Less is known about the role of $\mathrm{O}_{2} \mathrm{~b}^{1} \Sigma_{\mathrm{g}}{ }^{+}$in oxygen discharges, apart from the observation that it can be significantly populated by excitation transfer from $\mathrm{O}^{1} \mathrm{D}$ to $\mathrm{O}_{2} \mathrm{X}^{3} \Sigma_{\mathrm{g}}{ }^{-}$ [10-12], and that it can react with both $\mathrm{O}^{3} \mathrm{P}$ atoms and $\mathrm{O}_{3}$ [13]. Gudmundsson and co-workers [14-16] have proposed that $\mathrm{O}_{2} \mathrm{~b}^{1} \Sigma_{\mathrm{g}}{ }^{+}$could play an analogous role to $\mathrm{O}_{2} \mathrm{a}^{1} \Delta_{\mathrm{g}}$ in the destruction of negative ions, but no rate constant has been measured for such reactions. Notwithstanding, $\mathrm{O}_{2} \mathrm{~b}^{1} \Sigma_{\mathrm{g}}{ }^{+}$is likely to play non-negligible roles in both the neutral chemistry and the energy balance of oxygen discharges.

In order to experimentally investigate the kinetics of $\mathrm{O}_{2} \mathrm{~b}^{1} \Sigma_{\mathrm{g}}{ }^{+}$and its role in plasma dynamics a method for sensitive, absolute density measurements is needed. It has been detected previously by the weak, forbidden emission to the ground state at around 760nm[17]. However, this technique does not lend itself easily to absolute measurements, especially if the discharge occupies a large volume (such as low-pressure radiofrequency plasmas that are used for industrial surface processing). Therefore, we set out to develop an absorption spectroscopy scheme for the measurement of absolute $\mathrm{O}_{2} \mathrm{~b}^{1} \Sigma_{\mathrm{g}}{ }^{+}$density. The longest wavelength electric dipole transitions are in the vacuum ultraviolet, and the literature indicates the presence of several well-resolved Rydberg - singlet metastable transitions between 162 and $120 \mathrm{~nm}$, which are promising candidates for detection. However ground state oxygen has a strong continuum absorption in this region arising from the Schumann-Runge bands (see for example[18]) preventing use of the $130-170 \mathrm{~nm}$ region unless the overall $\mathrm{O}_{2}$ pressure is very low, so only the shortest wavelength transitions are likely to be of general use.

The Rydberg absorption spectra of the $\mathrm{b}^{1} \Sigma_{\mathrm{g}}{ }^{+}$state (along with the $\mathrm{a}^{1} \Delta_{\mathrm{g}}$ state) has been investigated in detail by Katayama et al[19], following on from previous studies by Alberti et $\mathrm{al}[20]$ and they identified clear, well-structured bands corresponding to the $3 \mathrm{p} \pi^{1} \Sigma_{\mathrm{u}}{ }^{+} \leftarrow \mathrm{b}^{1} \Sigma_{\mathrm{g}}{ }^{+}$ transition starting at $158 \mathrm{~nm}$ involving upper state vibration, $\mathrm{v}^{\prime},=0-4$ and also the $4 \mathrm{p} \pi^{1} \Sigma_{\mathrm{u}}{ }^{+} \leftarrow$ $\mathrm{b}^{1} \Sigma_{\mathrm{g}}{ }^{+}$transition starting at $135 \mathrm{~nm}$ involving $\mathrm{v}^{\prime}=0-2$. Many of the bands showed evidence of predissociation to varying extents, and some bands at shorter wavelength were perturbed. Forbidden transitions to some of these states have also been seen from the ground $\mathrm{X}^{3} \Sigma_{\mathrm{g}}{ }^{-}$state by Ogawa and Yamawaki[21] and transitions to the $3 \mathrm{p} \pi^{1} \Sigma_{\mathrm{u}}{ }^{+}$and $4 \mathrm{p} \pi^{1} \Sigma_{\mathrm{u}}{ }^{+}$states have been seen by two colour multiphoton ionization[22]. Note these states also been referred to as the $\mathrm{f}^{1} \Sigma_{\mathrm{u}}{ }^{+}$ (for $3 \mathrm{p} \pi^{1} \Sigma_{\mathrm{u}}^{+}$) and $\mathrm{j}^{1} \Sigma_{\mathrm{u}}^{+}\left(\right.$for $4 \mathrm{p} \pi^{1} \Sigma_{\mathrm{u}}^{+}$)[22,23] but the Rydberg style designation is used in this paper.

Given the observation of transitions to the $3 \mathrm{p} \pi^{1} \Sigma_{\mathrm{u}}{ }^{+}$and $4 \mathrm{p} \pi^{1} \Sigma_{\mathrm{u}}{ }^{+}$Rydberg states, transitions to the related $3 p \sigma^{1} \Pi_{\mathrm{u}}$ and $4 \mathrm{p} \sigma^{1} \Pi_{\mathrm{u}}$ Rydberg states might also be expected. However, the work of Katayama et al[19] suggests that they are diffuse, so that only a few were observed and definitive assignments were not given. One diffuse band at $161 \mathrm{~nm}$ was assigned to a ${ }^{1} \Pi_{\mathrm{u}}$ $\leftarrow \mathrm{b}^{1} \Sigma_{\mathrm{g}}{ }^{+}$transition, and other diffuse bands were assigned to ${ }^{1} \Pi_{\mathrm{u}} \leftarrow \mathrm{a}^{1} \Delta_{\mathrm{g}}$ transitions. A single structured ${ }^{1} \Pi_{\mathrm{u}} \leftarrow \mathrm{b}^{1} \Sigma_{\mathrm{g}}{ }^{+}$band was observed at $131 \mathrm{~nm}$, overlapping the $4 \mathrm{p} \pi^{1} \Sigma_{\mathrm{u}}{ }^{+} \leftarrow \mathrm{b}^{1} \Sigma_{\mathrm{g}}{ }^{+} 1-0$ band, which is presumably the $4 \mathrm{p} \sigma^{1} \Pi_{\mathrm{u}} 1-0$ band[24]. The $4 \mathrm{p} \sigma^{1} \Pi_{\mathrm{u}}$ state (also known as the $\mathrm{h}^{1} \Pi_{\mathrm{u}}$ 
state) has also been seen by two colour multiphoton ionization[22]. The $3 \mathrm{p} \pi^{1} \Delta_{\mathrm{u}}$ (also known as $\mathrm{e}^{1} \Delta_{\mathrm{u}}$ ) and $4 \mathrm{p} \pi^{1} \Delta_{\mathrm{u}}$ (also known as $\mathrm{i}^{1} \Delta_{\mathrm{u}}$ [22]) Rydberg states are also relevant, though they are only accessible from the $\mathrm{a}^{1} \Delta_{\mathrm{g}}$ state. The $3 \mathrm{p} \pi^{1} \Delta_{\mathrm{u}}-\mathrm{a}^{1} \Delta_{\mathrm{g}}$ transitions were identified by Ogawa and Yamawaki[21] and by later workers[23,25], and England et al[26] suggests that bands observed at 126.30 and $126.26 \mathrm{~nm}$ are the $4 \mathrm{p} \sigma^{1} \Pi_{\mathrm{u}}$ and $4 \mathrm{p} \pi^{1} \Delta_{\mathrm{u}} \mathrm{V}=0$ transitions from $\mathrm{a}^{1} \Delta_{\mathrm{g}} \mathrm{v}=0$. A summary of the states involved in this work is shown in Table 1.

Table 1 Summary of the electronic states of $\mathrm{O}_{2}$ relevant to this work ${ }^{\mathrm{a}}$

\begin{tabular}{|l|l|l|l|c|l|}
\hline Name & Alternate & $E(\mathrm{v}=0) / \mathrm{cm}^{-1}$ & $E(\mathrm{v}=1) / \mathrm{cm}^{-1}$ & $E(\mathrm{v}=1)-\mathrm{E}(\mathrm{v}=0) / \mathrm{cm}^{-1}$ & $B_{0} / \mathrm{cm}^{-1}$ \\
\hline $\mathrm{X}^{3} \Sigma_{\mathrm{g}}{ }^{-}$ & & $-0.25^{\mathrm{b}}$ & 1556.14 & 1556.39 & 1.43768 \\
\hline $\mathrm{a}^{1} \Delta_{\mathrm{g}}$ & & 7883.51 & 9372.57 & 1489.06 & 1.41784 \\
\hline $\mathrm{b}^{1} \Sigma_{\mathrm{g}}{ }^{+}$ & & 13122.01 & 14526.74 & 1404.73 & 1.39125 \\
\hline & & & & & \\
\hline $3 \mathrm{p} \sigma^{1} \Pi_{\mathrm{u}}$ & & 75167.5 & $76549(?)$ & $1382(?)$ & 1.598 \\
\hline $3 \mathrm{p} \pi^{1} \Delta_{\mathrm{u}}$ & $\mathrm{e}^{1} \Delta_{\mathrm{u}}$ & 75386.52 & 77210.66 & 1824.14 & 1.7881 \\
\hline $3 \mathrm{p} \pi^{1} \Sigma_{\mathrm{u}}^{+}$ & $\mathrm{f}^{1} \Sigma_{\mathrm{u}}{ }^{+}$ & 76263.464 & 78152.582 & 1889.119 & 1.69358 \\
\hline & & & & & \\
\hline $4 \mathrm{p} \sigma^{1} \Pi_{\mathrm{u}}$ & $\mathrm{h}^{1} \Pi_{\mathrm{u}}$ & 87086.6 & 89245.860 & 2159.3 & 1.43 \\
\hline $4 \mathrm{p} \pi^{1} \Delta_{\mathrm{u}}$ & $\mathrm{i}^{1} \Delta_{\mathrm{u}}$ & 87033.9 & 89153.95 & 2120.1 & 1.8544 \\
\hline $4 \mathrm{p} \pi^{1} \Sigma_{\mathrm{u}}{ }^{+}$ & $\mathrm{j}^{1} \Sigma_{\mathrm{u}}{ }^{+}$ & 87369.674 & 89264.123 & 1894.449 & 1.69863 \\
\hline
\end{tabular}

a Values for the low energy valence states taken from Yu et al[27]; other values from this work.

${ }^{\mathrm{b}}$ Energy scale in this work is such that the energy of the $J=0, \mathrm{v}=0$ level of the $\mathrm{X}^{3} \Sigma_{\mathrm{g}}{ }^{-}$state is zero.

The discussion above suggests the $3 \mathrm{p} \pi^{1} \Sigma_{\mathrm{u}}{ }^{+}-\mathrm{b}^{1} \Sigma_{\mathrm{g}}{ }^{+}$and $4 \mathrm{p} \pi^{1} \Sigma_{\mathrm{u}}{ }^{+}-\mathrm{b}^{1} \Sigma_{\mathrm{g}}{ }^{+}$transitions are the better characterised, and thus the more promising for use in spectroscopic determination. Of these, the $4 \mathrm{p} \pi^{1} \Sigma_{\mathrm{u}}{ }^{+}-\mathrm{b}^{1} \Sigma_{\mathrm{g}}{ }^{+}$is likely to be more generally useful because the $3 \mathrm{p} \pi^{1} \Sigma_{\mathrm{u}}{ }^{+}-\mathrm{b}^{1} \Sigma_{\mathrm{g}}{ }^{+}$ transition overlaps with the strong Schumann-Runge continuum from the ground state[28]. Prior to this work, absorption cross-sections have not been available for these transitions from the $\mathrm{b}^{1} \Sigma_{\mathrm{g}}{ }^{+}$state; the only absorption cross sections available for excited state $\mathrm{O}_{2}$ are for transitions originating from the $\mathrm{a}^{1} \Delta_{\mathrm{g}}$ state[28]. In this paper we use ab initio calculations to derive the cross-sections; for small molecules such calculations can give the accuracy required for transition moments reasonably easily, as the accuracy required is much less than for energies, for which spectroscopic accuracy is much harder to achieve. See for example reference [29], where $a b$ initio calculations are used as the basis for calculations of absolute transition intensities. The transitions studied here are more challenging to calculate, given the involvement of Rydberg states and the resulting high density of electronic states, but we show that useful results can be achieved. Conversion of ab initio transition moments to cross-sections requires a good knowledge of the rotational and vibrational structure (which we take from experiment rather than theory), particularly given the complicating presence of perturbations. We therefore also re-examine the $3 \mathrm{p} \pi^{1} \Sigma_{\mathrm{u}}{ }^{+}-\mathrm{b}^{1} \Sigma_{\mathrm{g}}{ }^{+}$and $4 \mathrm{p} \pi^{1} \Sigma_{\mathrm{u}}{ }^{+}-\mathrm{b}^{1} \Sigma_{\mathrm{g}}{ }^{+}$transitions using the high quality FT-VUV spectra available from the DESIRS beamline at the SOLEIL synchrotron, which allows significant refinement of the previous spectroscopic models. Additionally we reexamine some related transitions, including $3 \mathrm{p} \pi^{1} \Delta_{\mathrm{u}}-\mathrm{a}^{1} \Delta_{\mathrm{g}}$ and $4 \mathrm{p} \pi^{1} \Delta_{\mathrm{u}}-\mathrm{a}^{1} \Delta_{\mathrm{g}}$ though their diffuse nature implies that they are less suitable for the approach taken here.

\section{Experimental}

The measurements were conducted on the UV-VUV synchrotron beamline DESIRS at the synchrotron SOLEIL facility. DESIRS is equipped with a unique Fourier Transform 
spectrometer (FTS) that provides high spectral resolution and efficient data collection over a large UV-VUV spectral range, which has been described in detail elsewhere[30,31]. Briefly, the undulator source produces the incoming radiation with a typical spectral bandwidth $\Delta \lambda / \lambda=$ $7 \%$ corresponding to roughly $10 \mathrm{~nm}$ for a single spectral window in the VUV. The beam is directed toward the FTS branch which includes a multi-purpose environmental sample chamber, and subsequently the VUV-FTS instrument. In order to cover the spectral region of interest, 9 different spectral windows were recorded with various experimental conditions. The instrumental resolution was set to $0.27 \mathrm{~cm}^{-1}$ for most of the recorded spectra. A direct-current (DC) electric discharge inside a windowed cell was used for the production of $\mathrm{O}_{2}$ in its a ${ }^{1} \Delta_{\mathrm{g}}$ and $\mathrm{b}^{1} \Sigma_{\mathrm{g}}{ }^{+}$metastable states. A stabilized adjustable high voltage power supply unit of $6 \mathrm{kV}$ range was used to sustain the discharge. The cell, which is installed inside the vacuum chamber, is composed of a glass tube of $30 \mathrm{~cm}$ length and $10 \mathrm{~mm}$ inner diameter, sealed at both ends by $1 \mathrm{~mm}$ thick $\mathrm{MgF}_{2}$ windows. The theoretical transmission limit of $\mathrm{MgF}_{2}$ is $115 \mathrm{~nm}$. In practice, we were able to cover the VUV range down to $120 \mathrm{~nm}$. The cathode is a T-shaped stainless steel DN16 tube connected to the inside of the cell, and a stainless steel anode is mounted onto a cross-shaped glass holder at its opposite end. A $22 \mathrm{k} \Omega$ ballast resistor is installed in series with the discharge in order to stabilise the current during operation. All parts of the cell are cooled by a water circuit leading to a chiller outside the vacuum chamber. In operation, the external temperature of the cell was monitored, but never exceeded $350 \mathrm{~K}$. A gas mixture of $\mathrm{He}$ and $\mathrm{O}_{2}$ (purity $99.9995 \%$ ) was flowed constantly through the cell during operation, and pumped by a $600 \mathrm{~m}^{3} \mathrm{~h}^{-1}$ roots pump. He is used as a buffer gas to facilitate discharge ignition; it is totally transparent in the spectral region of interest.

The input flow of $\mathrm{He}$ and $\mathrm{O}_{2}$ was controlled by needle valves, and $\mathrm{O}_{2}$ entrance pressures from 0.05 mbar to 1 mbar were used depending on the spectral region. The longer wavelengths required lower pressures because of the Schumann-Runge continuum. Prior to each acquisition, a low resolution scan with the discharge off was recorded to check the background level. The current in the discharge was adjusted while observing the diffuse $3 p \pi^{1} \Delta_{u}-a^{1} \Delta_{g}$ (1-0) band at low spectral resolution, which indicated that values of 30-40 mA gave significant metastable state production, but further current increase did not provide any further improvement. Several strong absorption features from the $\mathrm{A}^{1} \Pi-\mathrm{X}^{1} \Sigma^{+}$transition in $\mathrm{CO}$ were also visible in our spectra, including hot bands. These bands were absent when the discharge is off, and the density of CO increased with the current, so the likely source of carbon atoms was the sputtering of the stainless steel electrodes. The $\mathrm{A}^{1} \Pi-\mathrm{X}^{1} \Sigma^{+} \mathrm{CO}$ spectrum is well known, and allowed the frequency calibration of the spectrometer to be verified using the energy levels tabulated by Niu et al[32,33]; this confirmed that no correction was required.

\section{$a b$ initio calculations of transition moments}

To obtain transition moments $a b$ initio calculations were performed using MOLPRO $2015.1[34,35]$. The calculations were targeted at the $4 \mathrm{p} \pi^{1} \Sigma_{\mathrm{u}}{ }^{+}-\mathrm{b}^{1} \Sigma_{\mathrm{g}}{ }^{+}$transition, but to avoid root-flipping and other problems, all states of the same symmetry and spin below the directlyinvolved states were also calculated. Since MOLPRO uses $\mathrm{D}_{2 \mathrm{~h}}$ symmetry internally, $\Delta$ states must also be included in the calculated set therefore the calculations also included the $\mathrm{a}^{1} \Delta_{\mathrm{g}}$ valence state and the $3 p \pi^{1} \Sigma_{\mathrm{u}}^{+}, 3 \mathrm{p} \pi^{1} \Delta_{\mathrm{u}}$ and $4 \mathrm{p} \pi^{1} \Delta_{\mathrm{u}}$ Rydberg states. Targeting calculations on the $4 p \sigma^{1} \Pi_{u}$ state was also considered, since this state is also considered in the analysis below, but initial calculations were not promising (due to crossings with valence states at longer bond lengths limiting the possible calculations) so this was not pursued. The Rydberg states required the use of a diffuse basis; the bulk of the calculations were performed with the doubly augmented cc-pVTZ basis from Woon and Dunning[36] from the EMSL basis set exchange[37] further augmented by an additional diffuse function for each $l$. This basis is 
denoted by tAVTZ below. The active space also had to be increased, with a minimum of two additional $\pi_{\mathrm{u}}$ orbitals required to account for the $3 \mathrm{p} \pi$ and $4 \mathrm{p} \pi$ Rydberg states. Initially, multi configuration self-consistent field (MCSCF) calculations[38,39] were performed, state averaged over the six states. These calculations were followed by multi-reference configuration interaction (MRCI) calculations[40,41] on each of the two symmetries required, based on the MCSCF calculations. The final energies used include the relaxed Davidson correction[35]. Transition dipole moments and spin-orbit matrix elements were also calculated, the later using the Breit-Pauli Hamiltonian. To investigate convergence with respect to basis set size and active space, a series of calculations, tabulated in Table S1, were performed at a bond length, $r$, of $1.04 \AA$. (This is slightly shorter than the equilibrium bond length of the Rydberg states, and is positioned to avoid crossings between states). These suggest the energies are converged to $\sim 100 \mathrm{~cm}^{-1}$ and the transition moments to perhaps $\sim 0.02$ Debye. We were somewhat limited in the tests we could perform, given the size of the calculations. However, in an active space including two additional $\pi_{\mathrm{u}}$ orbitals, extending the basis set with an additional set of diffuse functions (tAVTZ to qAVTZ) made only a small difference. Increasing the active space with an additional $\pi_{\mathrm{g}}$ orbital did make a noticeable difference, but further additional orbitals had only a small effect. Finally, the tAVTZ basis, with an active space including two additional $\pi_{\mathrm{u}}$ orbitals and one additional $\pi_{\mathrm{g}}$ orbital was used to calculate the potential energy curves. The curves were calculated over the bond length range of $0.86-1.44 \AA$. The upper limit is slightly shorter than desirable, but crossings with other states, typically valence states, meant it was not possible to extend the Rydberg state calculations to longer range. The $\mathrm{a}^{1} \Delta_{\mathrm{g}}$ and $\mathrm{b}^{1} \Sigma_{\mathrm{g}}{ }^{+}$state calculations were extended to longer range using an AV6Z basis using the default active space.

The final calculated state energies with respect to the $\mathrm{a}^{1} \Delta_{\mathrm{g}}$ state are reasonable for $a b$ initio calculations, agreeing with the experimental values to within $200 \mathrm{~cm}^{-1}$ for the $\mathrm{b}^{1} \Sigma_{\mathrm{g}}{ }^{+}$state and to within $2000 \mathrm{~cm}^{-1}$ for the Rydberg states. The accuracy of the separations between the Rydberg states are much better, suggesting a relative accuracy of $\sim 200 \mathrm{~cm}^{-1}$. The $3 \mathrm{p} \pi^{1} \Delta_{\mathrm{u}}$ state is calculated to be $680 \mathrm{~cm}^{-1}$ below the $3 \mathrm{p} \pi^{1} \Sigma_{\mathrm{u}}{ }^{+}$state, compared to the experimental value of $875 \mathrm{~cm}^{-1}$ for the $\mathrm{v}=0$ level. The $4 \mathrm{p} \pi^{1} \Delta_{\mathrm{u}}$ state is calculated to be $\sim 300 \mathrm{~cm}^{-1}$ below the $4 \mathrm{p} \pi^{1} \Sigma_{\mathrm{u}}^{+}$ state compared with the observed $\mathrm{v}=1$ levels (the only clear level) having a $110 \mathrm{~cm}^{-1}$ separation. The gap between the ${ }^{1} \Delta_{\mathrm{u}}$ and ${ }^{1} \Sigma_{\mathrm{u}}{ }^{+}$states will be reduced by the spin-orbit induced singlet-triplet mixing (discussed for the $4 \mathrm{p}$ case by England et al[26]), but the estimated shift is only $20 \mathrm{~cm}^{-1}$.

The quality of the potential energy curves can be directly assessed by comparing with the observed vibrational intervals and rotational constants given in Table 2.The $a b$ initio columns in the table are calculated from the potential energy curves using Le Roy's LEVEL program[42]. This shows that the ab initio calculation is in very good agreement for the $\mathrm{a}^{1} \Delta_{\mathrm{g}}$ and $\mathrm{b}^{1} \Sigma_{\mathrm{g}}{ }^{+}$states, and only slightly worse for the for the $3 \mathrm{p} \pi^{1} \Sigma_{\mathrm{u}}{ }^{+}$and $4 \mathrm{p} \pi^{1} \Sigma_{\mathrm{u}}{ }^{+}$states. To produce the final potential energy curves for the calculation, the curves were shifted by $0.0059,0.0076$ and $0.0123 \AA$ respectively to shorter distance, and the energies linearly scaled by 1.0211 , 1.0297 and 1.0565 giving the "Adjusted" rows in Table 2. A similar process was applied to the $3 \mathrm{p} \pi^{1} \Delta_{\mathrm{u}}$ and $4 \mathrm{p} \pi^{1} \Delta_{\mathrm{u}}$ states, though the possible adjustment was limited because the experimental data was not so clear. The final potential energy curves and transition moments are provided in tables S2-S11 of the supplementary information, and plotted in Figure 1. 


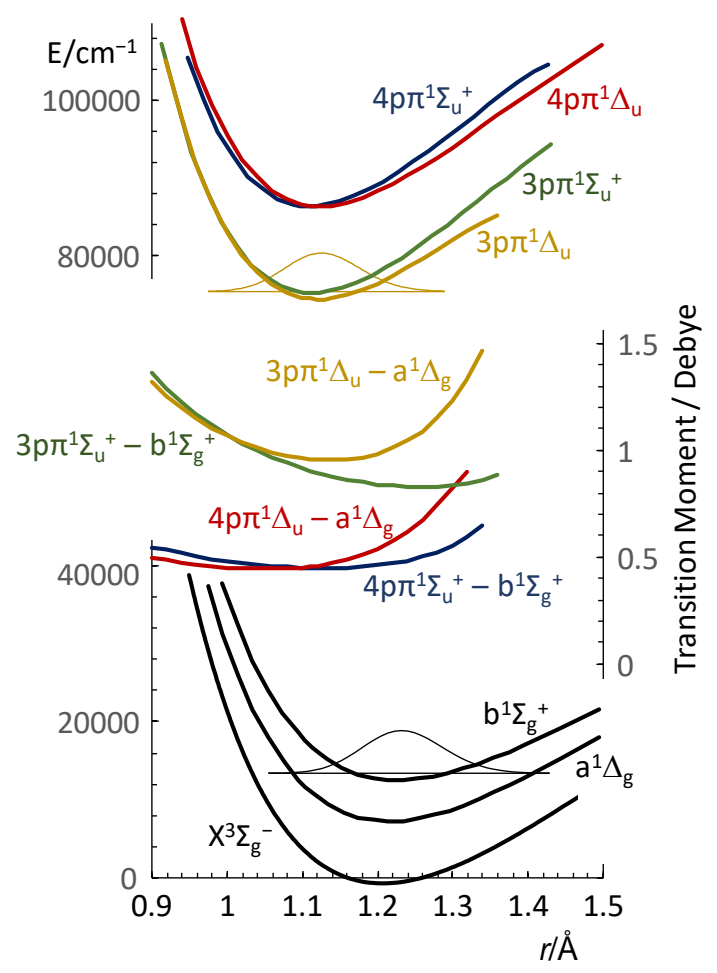

Figure 1 Potential energy curves and transition dipole moments for $\mathrm{O}_{2}$. Selected vibrational wavefunctions are indicated on the plot.

The transition dipole moments for individual vibrational bands were then calculated by numerically integrating the transition dipole moment over the vibrational wavefunctions calculated from the potential energy curves by Le Roy's LEVEL program[42]. This is similar to a traditional Franck-Condon factor calculation, but more accurate because the $r$-dependence of the transition dipole moment is fully taken into account. Using the unadjusted $a b$ initio potential energy curves gave a transition moment for the 1-0 band of the $4 p \pi^{1} \Sigma_{\mathrm{u}}^{+}-\mathrm{b}^{1} \Sigma_{\mathrm{g}}{ }^{+}$transition of 0.239 Debye. Using the potential energy curve adjustments described above made a small reduction to the 1-0 transition moment to 0.215 Debye. As mentioned above, the $a b$ initio values only extended to $1.44 \AA$, but the vibrational transition moments were verified to be insensitive (with changes $<0.001$ Debye) to different assumptions about extrapolations to longer bond lengths. The final calculated values of the $n \mathrm{p} \pi^{1} \Sigma_{\mathrm{u}}{ }^{+}-\mathrm{b}^{1} \Sigma_{\mathrm{g}}{ }^{+}$transition moments are given in Table 3 and Table 4 . Transition moments calculated the same way for the $n \mathrm{p} \pi^{1} \Delta_{\mathrm{u}}-\mathrm{a}^{1} \Delta_{\mathrm{g}}$ transitions are given in Table 5 and Table 6.

An important final consideration is the mixing between electronic states due to effects not included in the ab initio calculations. An obvious consideration here is spin-orbit coupling, which is well known to cause strong mixing between Rydberg states; see for example the work of Ogorzalek Loo et al[43] who discuss quantitatively the mixing within the $3 \mathrm{~d} \pi_{\mathrm{g}}$ Rydberg states, where the ${ }^{1} \Sigma_{\mathrm{g}}{ }^{+}$state contains $6 \%$ of the ${ }^{3} \Sigma_{\mathrm{g}}{ }^{-}$state. There is also a more recent paper by Lewis et al [44] which discusses the states of interest here. The ab initio calculations provide enough information to calculate this mixing, specifically mixing of the $4 \mathrm{p} \pi^{1} \Sigma_{\mathrm{u}}{ }^{+}$state with the $4 \mathrm{p} \pi^{3} \Sigma_{\mathrm{u}}{ }^{-}$state. The calculations give the spin-orbit matrix element mixing the states in the range $83-87 \mathrm{~cm}^{-1}$; this is, as expected, close to the half of the spin orbit splitting in the ion core, and is insensitive to the quality of the calculation of the Rydberg states. The other quantity required is the singlet-triplet splitting for these two states, which the calculations give in the range of $505-535 \mathrm{~cm}^{-1}$. Together these imply a small reduction in the 1-0 transition moment to 0.212 Debye. If a splitting of $300 \mathrm{~cm}^{-1}$ is assumed, consistent with the $200 \mathrm{~cm}^{-1}$ relative error 
discussed above, then the transition moment further reduces to 0.208 Debye. For the $3 p \pi$ states the singlet-triplet slitting is larger $\left(\sim 1400 \mathrm{~cm}^{-1}\right)$ so can be ignored.

Apart from the most significant spin-orbit coupling discussed above, other interactions between electronic states are ignored. Previous work, and the analysis below, show that more interactions are clearly present for some bands and states, and one of the purposes of the spectroscopic analysis is to identify those strongly affected by other states. A significant contribution to this will be interactions with valence states[44], which typically lead to predissociation of the Rydberg states, as well as being responsible for the limited range of bond lengths covered by the ab initio calculations. 
Table 2 Observed and calculated vibrational intervals and rotational constants $\left(/ \mathrm{cm}^{-1}\right)$ for selected electronic states of $\mathrm{O}_{2}$

\begin{tabular}{|c|c|c|c|c|c|c|c|c|c|c|c|c|c|c|c|c|}
\hline & \multicolumn{3}{|c|}{$\mathrm{a}^{1} \Delta_{\mathrm{g}}$} & \multicolumn{3}{|c|}{$\mathrm{b}^{1} \sum_{\mathrm{g}}{ }^{+}$} & \multicolumn{3}{|c|}{$3 \mathrm{p} \pi^{1} \Sigma_{\mathrm{u}^{+}}$} & \multicolumn{3}{|c|}{$4 \mathrm{p} \pi^{1} \Sigma_{\mathrm{u}^{+}}$} & \multicolumn{3}{|c|}{$3 \mathrm{p} \pi^{1} \Delta_{\mathrm{u}}$} & $4 \mathrm{p} \pi^{1} \Delta_{\mathrm{u}}$ \\
\hline & Observed $^{\mathrm{a}}$ & $a b$ initio & Adjusted & Observed $^{\mathrm{a}}$ & $a b$ initio & Adjusted & Observed $^{\mathrm{b}}$ & $a b$ initio & Adjusted & Observed $^{\mathrm{b}}$ & $a b$ initio & Adjusted & Observed $^{\mathrm{b}}$ & $a b$ initio & Adjusted & $a b$ initio \\
\hline$G(1)-G(0)$ & 1483.5 & 1474.1 & 1483.6 & 1404.7 & 1390.2 & 1405.1 & 1889.1 & 1861.6 & 1889.6 & 1894.5 & 1843.1 & 1895.4 & 1824.1 & 1834.6 & 1824.6 & 1827.6 \\
\hline$G(2)-G(1)$ & 1457.4 & 1447.3 & 1456.8 & 1376.8 & 1362.8 & 1377.7 & 1849.7 & 1826.4 & 1854.4 & - & 1809.0 & 1861.3 & 1708.4 & 1789.6 & 1779.5 & 1780.6 \\
\hline$G(3)-G(2)$ & 1431.3 & 1423.4 & 1432.8 & 1348.7 & 1340.3 & 1355.1 & 1821.5 & 1791.7 & 1819.7 & - & 1776.2 & 1828.6 & - & 1740.7 & 1730.5 & 1730.4 \\
\hline$G(4)-G(3)$ & 1405.2 & 1400.3 & 1409.8 & 1320.5 & 1317.2 & 1332.2 & 1777.1 & 1755.9 & 1783.9 & - & 1740.8 & 1793.2 & - & 1682.3 & 1671.9 & 1680.2 \\
\hline$B(0)$ & 1.41784 & 1.40594 & 1.41791 & 1.39125 & 1.37817 & 1.39146 & 1.69358 & 1.67055 & 1.69370 & 1.69863 & 1.66196 & 1.69911 & 1.7881 & 1.66617 & 1.66612 & 1.65900 \\
\hline$B(1)$ & 1.40072 & 1.38910 & 1.40099 & 1.37296 & 1.35995 & 1.37320 & 1.67448 & 1.65069 & 1.67379 & 1.67293 & 1.64204 & 1.67918 & 1.628 & 1.64505 & 1.64487 & 1.63813 \\
\hline$B(2)$ & 1.38359 & 1.37205 & 1.38387 & 1.35460 & 1.34217 & 1.35538 & 1.65048 & 1.63075 & 1.65380 & - & 1.62234 & 1.65948 & 1.437 & 1.62239 & 1.62208 & 1.61531 \\
\hline$B(3)$ & 1.36645 & 1.35539 & 1.36713 & 1.33613 & 1.32512 & 1.33831 & 1.63172 & 1.61066 & 1.63366 & - & 1.60238 & 1.63955 & - & 1.59817 & 1.59768 & 1.59124 \\
\hline$B(4)$ & 1.34929 & 1.33901 & 1.35069 & 1.31751 & 1.30705 & 1.32025 & 1.60851 & 1.59021 & 1.61316 & - & 1.58211 & 1.61928 & - & 1.57043 & 1.56970 & 1.56827 \\
\hline$D(0) \times 10^{-6}$ & 5.10 & 5.04 & 5.10 & 5.37 & 5.33 & 5.37 & 6.16 & 5.30 & 5.36 & 8.56 & 5.32 & 5.38 & - & 5.41 & 5.47 & 5.38 \\
\hline$D(1) \times 10^{-6}$ & 5.12 & 5.07 & 5.13 & 5.40 & 5.36 & 5.40 & 5.04 & 5.35 & 5.41 & 9.68 & 5.36 & 5.42 & - & 5.54 & 5.60 & 5.54 \\
\hline$D(2) \times 10^{-6}$ & 5.14 & 5.04 & 5.11 & 5.44 & 5.30 & 5.34 & 6.09 & 5.39 & 5.45 & - & 5.39 & 5.44 & - & 5.72 & 5.78 & 5.73 \\
\hline$D(3) \times 10^{-6}$ & 5.15 & 5.03 & 5.09 & 5.47 & 5.29 & 5.32 & - & 5.46 & 5.52 & - & 5.47 & 5.52 & - & 6.05 & 6.12 & 5.92 \\
\hline$D(4) \times 10^{-6}$ & 5.17 & 5.10 & 5.16 & 5.50 & 5.50 & 5.53 & 9.53 & 5.51 & 5.57 & - & 5.51 & 5.55 & - & 6.65 & 6.74 & 5.61 \\
\hline
\end{tabular}

${ }^{\mathrm{a}}$ Low energy valence states taken from $\mathrm{Yu}$ et al[27]

${ }^{b}$ This work 
Table 3 Calculated transition moments (/Debye) for the $3 \mathrm{p} \pi^{1} \Sigma_{\mathrm{u}}{ }^{+}-\mathrm{b}^{1} \Sigma_{\mathrm{g}}{ }^{+}$transition in $\mathrm{O}_{2}$

\begin{tabular}{ccccccc} 
& \multicolumn{6}{c}{$3 \mathrm{p} \pi^{1} \Sigma_{\mathrm{u}}{ }^{+} \mathrm{v}^{\prime}$} \\
$\mathrm{b}^{1} \Sigma_{\mathrm{g}}{ }^{+} \mathrm{v}^{\prime \prime}$ & 0 & 1 & 2 & 3 & 4 & \multicolumn{1}{c}{5} \\
0 & 0.2340 & -0.4012 & 0.4572 & -0.3977 & 0.2781 & -0.1599 \\
1 & 0.3486 & -0.3657 & 0.1169 & 0.1975 & -0.3814 & 0.3845 \\
2 & 0.3916 & -0.1848 & -0.1883 & 0.3033 & -0.0866 & -0.2217 \\
3 & 0.3815 & 0.0132 & -0.2891 & 0.0925 & 0.2273 & -0.2482 \\
4 & 0.3405 & 0.1646 & -0.2267 & -0.1344 & 0.2391 & 0.0480 \\
5 & 0.2868 & 0.2535 & -0.0915 & -0.2403 & 0.0670 & 0.2274
\end{tabular}

Table 4 Calculated transition moments (/Debye) for the $4 \mathrm{p} \pi^{1} \Sigma_{\mathrm{u}}{ }^{+}-\mathrm{b}^{1} \Sigma_{\mathrm{g}}{ }^{+}$transition in $\mathrm{O}_{2}$

Table 5 Calculated transition moments (/Debye) for the $3 \mathrm{p} \pi^{1} \Delta_{\mathrm{u}}-\mathrm{a}^{1} \Delta_{\mathrm{g}}$ transition in $\mathrm{O}_{2}$

\begin{tabular}{ccccccc}
\multicolumn{7}{c}{$3 \mathrm{p} \pi^{1} \Delta_{\mathrm{u}} \mathrm{v}^{\prime}$} \\
$\mathrm{a}^{1} \Delta_{\mathrm{g} \mathrm{V}}$ " & 0 & 1 & 2 & 3 & \multicolumn{1}{c}{4} & \multicolumn{1}{c}{5} \\
0 & 0.4043 & -0.5922 & 0.5681 & -0.4050 & 0.2215 & -0.0899 \\
1 & 0.4866 & -0.2874 & -0.2024 & 0.5545 & -0.5867 & 0.3997 \\
2 & 0.4547 & 0.0441 & -0.3845 & 0.1136 & 0.4200 & -0.7013 \\
3 & 0.3761 & 0.2526 & -0.2339 & -0.2440 & 0.2700 & 0.3002 \\
4 & 0.2895 & 0.3370 & -0.0040 & -0.3118 & -0.0542 & 0.2886 \\
5 & 0.2123 & 0.3382 & 0.1734 & -0.1812 & -0.2609 & 0.0958
\end{tabular}

Table 6 Calculated transition moments (/Debye) for the $4 \mathrm{p} \pi^{1} \Delta_{\mathrm{u}}-\mathrm{a}^{1} \Delta_{\mathrm{g}}$ transition in $\mathrm{O}_{2}$

\begin{tabular}{ccccccc} 
& \multicolumn{6}{c}{$4 \mathrm{p} \pi^{1} \Delta_{\mathrm{u}} \mathrm{v}^{\prime}$} \\
$\mathrm{a}^{1} \Delta_{\mathrm{g}} \mathrm{V}$ & 0 & 1 & 2 & 3 & 4 & \multicolumn{1}{c}{5} \\
0 & 0.2213 & -0.3323 & 0.3315 & -0.2484 & 0.1429 & -0.0615 \\
1 & 0.2484 & -0.1332 & -0.1416 & 0.3466 & -0.3675 & 0.2540 \\
2 & 0.2193 & 0.0429 & -0.2059 & 0.0360 & 0.2679 & -0.4123 \\
3 & 0.1730 & 0.1368 & -0.0995 & -0.1584 & 0.1598 & 0.1340 \\
4 & 0.1276 & 0.1661 & 0.0180 & -0.1511 & -0.0770 & 0.2303 \\
5 & 0.0900 & 0.1569 & 0.0982 & -0.0703 & -0.1461 & 0.0162
\end{tabular}




\section{The $3 \mathrm{p} \pi^{1} \Delta_{\mathrm{u}}-\mathrm{a}^{1} \Delta_{\mathrm{g}}$ transition}

The $3 \mathrm{p} \pi^{1} \Delta_{\mathrm{u}}-\mathrm{a}^{1} \Delta_{\mathrm{g}}$ transitions provide a useful quality check of the calculations, since measured cross sections are available from Ogawa and Ogawa[28]. The 0-0, 1-0 and 2-0 bands show clearly in our spectra (Figure 2), although they are all diffuse, with no observable structure, consistent with previous work. The spectrum also shows three bands attributable to the $3 \mathrm{p} \sigma^{1} \Pi_{\mathrm{u}}-\mathrm{a}^{1} \Delta_{\mathrm{g}}$ transition, and weak (sharp) features from $\mathrm{b}^{1} \Sigma_{\mathrm{g}}{ }^{+}$state, which are discussed in later sections. (This spectrum was recorded under discharge conditions producing little $\mathrm{b}^{1} \Sigma_{\mathrm{g}}{ }^{+}$ state.) A good simulation of the broad bands can be produced using a simple, single state model. The fits for selected bands could be improved by adding a $J$ dependence to the dipole moment using the $A_{1}$ parameter defined by Watson[45]. An alternative way of improving the fits was to allow a $J$ dependence of the linewidth, allowing it to vary as $w=k_{0}+k_{J} J(J+1)$. Both effects are clearly observed in more resolved bands discussed below, but since individual rotational lines are not resolved here it is not possible to unambiguously distinguish the two, so the best fit was taken.

The results of contour fits directly to the measured absorbances of these bands using the PGOPHER program[46] are presented in Table 7. The ground state parameters were taken from Yu et al[27]. The effective instrument lineshape is included in the model using a Gaussian (with typical full width at half maximum $0.27 \mathrm{~cm}^{-1}$ ) giving an overall Voigt profile for the individual rotational lines. (Strictly the instrumental lineshape is a sinc function but the signal to noise is such that the distinction is not significant for the $\mathrm{O}_{2}$ lines.) Figure 2 shows a single experimental spectrum; some fits to different recordings of the same bands are included in the supplementary information. Comparing the results of these fits with those tabulated in Table 7 suggests that the purely statistical errors provided by the least squares fitting procedure are too small; a better reflection of the true uncertainties is had by increasing these by a factor of up to $\sim 5$. This allows for factors not included in the model, such as imperfect baseline subtraction in the experimental spectra, and an over-simplified model of the $J$ dependence of the linewidth.

Figure 2 shows a single experimental spectrum, which allows the relative intensities of the three bands to be compared directly. Table 7 includes transition dipole moments for the three vibronic bands, scaled to the ab initio value for the 1-0 band. The values are reasonably consistent, confirming the accuracy of the relative transition moment calculation. This also alleviates an important concern, which is that intensity may be lost or gained by mixing with other states. Some state mixing must be present to give the observed predissociation, and the fact that the observed variation of rotational constants with $\mathrm{v}$ is stronger than that predicted by the ab initio calculations is also diagnostic of mixing. The varying widths and rotational constants imply that the state mixing is significantly state-dependent, but the small variation of the ratio of observed and calculated transition dipole moments suggests the net effect on intensity is relatively small.

Table 7 Parameters ${ }^{\mathrm{a}}$ of the $3 \mathrm{p} \pi^{1} \Delta_{\mathrm{u}}$ state of $\mathrm{O}_{2}$

\begin{tabular}{|c|c|c|c|c|c|c|}
\hline & Origin $/ \mathrm{cm}^{-1}$ & $B / \mathrm{cm}^{-1}$ & $k_{0} / \mathrm{cm}^{-1}$ & $A_{1} \times 10^{-3}$ & $\mu /$ Debye & $\mu_{\mathrm{obs}} / \mu_{\mathrm{calc}}$ \\
\hline $\mathrm{v}=0$ & $75386.52(8)$ & $1.7881(9)$ & $12.0(2)$ & $3.7(3)$ & $0.3384(5)$ & 0.837 \\
\hline $\mathrm{V}=1$ & $77210.66(8)$ & $1.628(11)$ & $17.95(6)$ & $0^{\mathrm{c}}$ & $-0.5922^{c}$ & $1^{\mathrm{c}}$ \\
\hline $\mathrm{v}=2$ & 78919.1(4) & $1.437(3)$ & $127.9(5)$ & $0^{\mathrm{c}}$ & $0.6124(8)$ & 1.078 \\
\hline
\end{tabular}

${ }^{a}$ Figures in parentheses are standard deviations in units of the last significant figure; as discussed in the text these probably should be scaled up by at least 5 .

${ }^{\mathrm{b}}$ Relative to the $J=0, \mathrm{v}=0$ level of the $\mathrm{X}^{3} \Sigma_{\mathrm{g}}{ }^{-}$state.

${ }^{\mathrm{c}}$ Fixed 


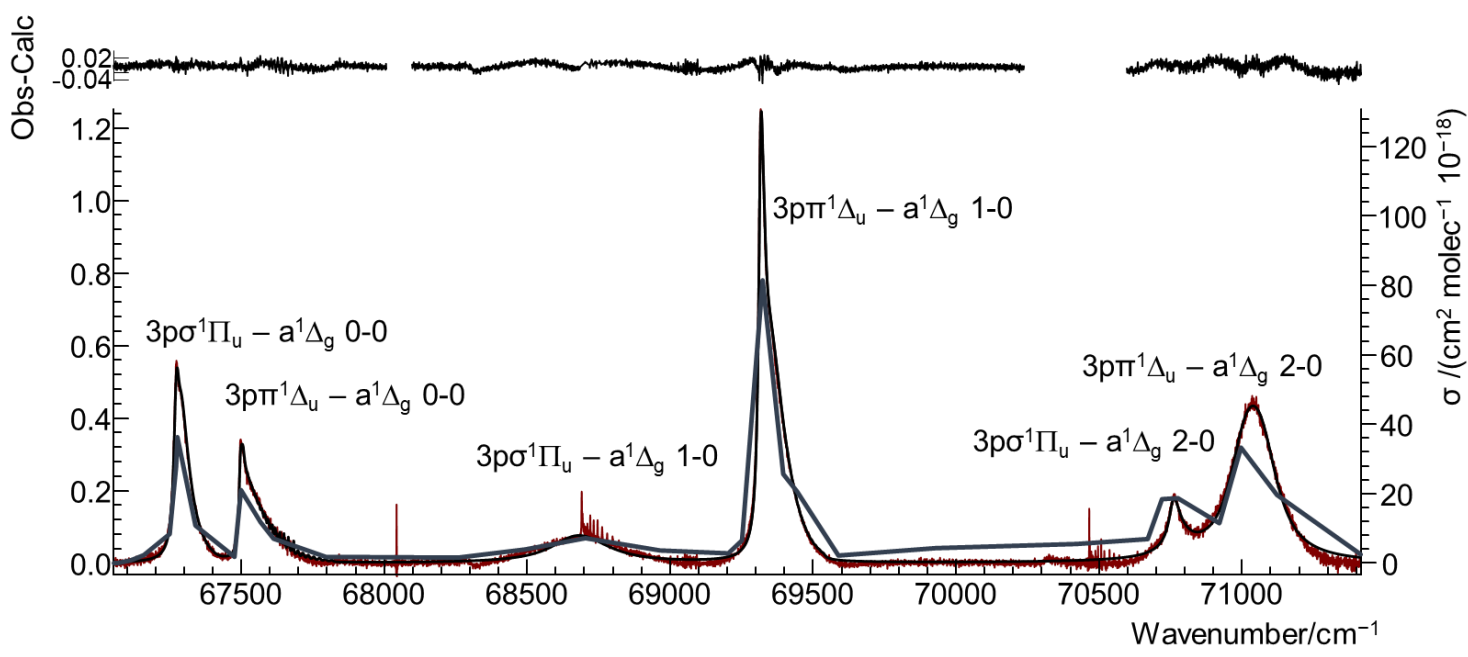

Figure 2 The $0-0,1-0$ and 2-0 bands of the $3 p \pi^{1} \Delta_{u}-a^{1} \Delta_{g}$ transition in $\mathrm{O}_{2}$. The lower plots show the experimental spectra (in red, left axis), calculated cross sections (thick black line, right axis) and cross sections measured by Ogawa and Ogawa[28] (thick grey line, right axis). The upper plots show the residuals from the fits.

For confirmation of the absolute amplitudes of our simulations, we can compare to the cross sections measured by Ogawa and Ogawa[28], also shown in Figure 2. The previous cross sections were measured using a bandwidth of $0.0014 \mathrm{~nm}$ though this is not crucial to the comparion. The temperature of the measured cross sections is not clear, so we have used a value of $315 \mathrm{~K}$ as in our own measurements, as the apparatus is similar. Note that the calculated absorption cross-sections assume that all of the population of the $\mathrm{a}^{1} \Delta_{\mathrm{g}}$ state is in the $\mathrm{v}=0$ level. The agreement is promising, but the spacing of the data points of Ogawa and Ogawa is rather wide (typically $5 \AA$ with some intermediate spot values near the band maxima) so it is difficult to make a quantitative comparison, though scaling the previous work up by a factor of about 1.4 would give better agreement. Preliminary analysis of measurements (which will be presented elsewhere[47]) of the VUV absorption of $\mathrm{O}_{2}$ DC discharges using the monochromatic branch at DESIRS, have allowed the determination of the $\mathrm{O}_{2}$ a density independent of any knowledge of the line strength. These results also suggest that the previous cross-sections should be increased by a factor of about 1.5, in excellent agreement with these calculations. Overall, the results for the $3 \mathrm{p} \pi^{1} \Delta_{\mathrm{u}}-\mathrm{a}^{1} \Delta_{\mathrm{g}}$ bands provide good, if not conclusive, validation of the approach used here for determining transition moments.

\section{Rotational analysis of the $4 p \pi^{1} \Sigma_{\mathrm{u}}{ }^{+}-b^{1} \Sigma_{\mathrm{g}}{ }^{+}$transition}

Both the $0-0$ and 1-0 bands of this transition show sharp structure that has been analysed previously by Katayama et al[19], and both of these bands showed clearly in our spectra. A weak feature at $128.268 \mathrm{~nm}$, attributed by Katayama et al[19] to the 2-0 band, was also visible in our spectra, but with no structure and a linewidth of at least $5 \mathrm{~cm}^{-1}$, so we did not attempt analysis of this band because the signal to noise ratio was not sufficient.

$4 p \pi^{1} \Sigma_{u}^{+} v^{\prime}=0$

The origin band at $134.7 \mathrm{~nm}$ shows no evidence of perturbations, but unfortunately in our spectra showed significant interference from the $7-0$ band of the $A^{1} \Pi-X^{1} \Sigma^{+}$transition of $\mathrm{CO}$. While the $\mathrm{A}^{1} \Pi$ state of $\mathrm{CO}$ shows many perturbations [48] it was possible to simulate the CO 7-0 band in our spectra without considering them. A detailed inspection of the spectrum shows that the $\mathrm{O}_{2}$ lines are consistently wider than the $\mathrm{CO}$ lines. A band contour fit performed 
by the PGOPHER program[46] to both the $\mathrm{CO}$ and $\mathrm{O}_{2}$ transitions gave good results using a $J$ independent extra width for $\mathrm{O}_{2}$, providing the parameters given in Table 8 . The ground state parameters were taken from $\mathrm{Yu}$ et al[27]. The values in Table 8 are entirely consistent with the values given by Katayama et al[19], but more precise. Figure 3 shows the experimental spectrum and a simulation of the region round the band head.

Table 8 Rotational Parameters ${ }^{\mathrm{a}}\left(/ \mathrm{cm}^{-1}\right)$ of $\mathrm{v}=0$ of the $4 \mathrm{p} \pi^{1} \Sigma_{\mathrm{u}}{ }^{+}$state of $\mathrm{O}_{2}$

\begin{tabular}{|l|l|}
\hline Parameter & Value $/ \mathrm{cm}^{-1}$ \\
\hline Origin $^{\mathrm{b}}$ & $87369.674(4)$ \\
\hline$B$ & $1.69863(6)$ \\
\hline$D \times 10^{6}$ & $8.56(8)$ \\
\hline Width & $0.289(6)$ \\
\hline
\end{tabular}

${ }^{a}$ Figures in parentheses are standard deviations in units of the last significant figure; as discussed in the text these should probably be scaled up by at least 5 .

${ }^{\mathrm{b}}$ Relative to the $J=0, \mathrm{v}=0$ level of the $\mathrm{X}^{3} \Sigma_{\mathrm{g}}{ }^{-}$state.

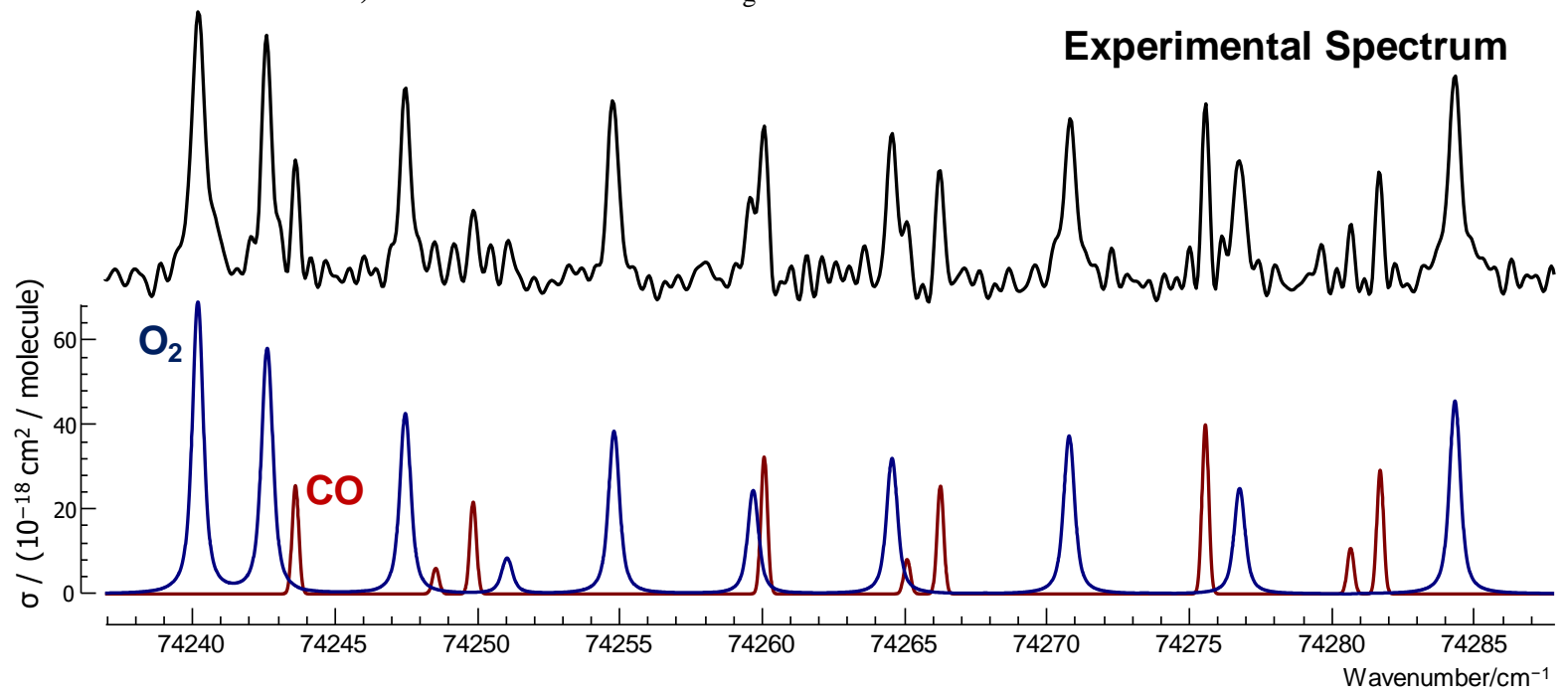

Figure 3 Experimental spectrum (upper trace) and simulation (blue curve in the lower trace) of the region round the band head of the origin band of the $4 \mathrm{p} \pi^{1} \Sigma_{\mathrm{u}}{ }^{+}-\mathrm{b}^{1} \Sigma_{\mathrm{g}}{ }^{+}$transition in $\mathrm{O}_{2}$. Several lines from the $7-0$ band of the $\mathrm{A}^{1} \Pi-\mathrm{X}^{1} \Sigma^{+}$transition of $\mathrm{CO}$ are also present in the experimental spectrum and are shown in a simulation (red curve). Note the $\mathrm{O}_{2}$ lines are consistently broader than the $\mathrm{CO}$ lines, which are instrument limited.

$4 p \pi^{1} \Sigma_{u}^{+} v^{\prime}=1$

The $1-0$ band is more awkward, as the upper state is close in energy to a ${ }^{1} \Pi_{u}$ state that, as identified by Katayama et al[19], appears in the absorption spectrum and also perturbs the $4 \mathrm{p} \pi^{1} \Sigma_{\mathrm{u}}{ }^{+}$state. The same ${ }^{1} \Pi_{\mathrm{u}}$ state was observed by Alberti et al[20] in absorption from the $\mathrm{a}^{1} \Delta_{\mathrm{g}}$ state in a band at $122.9 \mathrm{~nm}$. The most likely candidate for this state is $v=1$ of $4 p \sigma^{1} \Pi_{u}$. Other observations of this $4 \mathrm{p} \sigma^{1} \Pi_{\mathrm{u}}$ electronic state include an assignment by England et al[26] of three sharp transitions in the absorption spectrum from the ground $\mathrm{X}^{1} \Sigma_{\mathrm{g}}{ }^{+}$state, with the intensity arising from mixing with an adjacent $4 p \sigma^{3} \Pi_{u}$ state, possibly $v=1$ of the $\mathrm{F}^{3} \Pi_{\mathrm{u}}$ state. These three sharp lines corresponded to $J^{\prime}=1$, with all the other lines showing significant predissociation by a state assigned by these workers as the $4 \mathrm{p} \pi^{1} \Delta_{\mathrm{u}}$ state. The term values for the $J^{\prime}=1$ levels observed by England et al are $2156.1 \mathrm{~cm}^{-1}$ below the $J^{\prime}=1$ levels measured here, suggesting we are observing one vibrational level higher, $\mathrm{v}=1$. 
Yamawaki[24] has also identified a ${ }^{1} \Delta_{\mathrm{u}}$ state lying below the ${ }^{1} \Pi_{\mathrm{u}}$ state that may perturb the ${ }^{1} \Pi_{u}$ state. The state was assigned as $4 p \pi^{1} \Delta_{u} v=1$, and Yamawaki observed a weak absorption to this state from the $\mathrm{a}^{1} \Delta_{\mathrm{g}}$ state at $123.05 \mathrm{~nm}$. The band was diffuse, but nevertheless sufficiently resolved to show rotational structure in the R branch. The 1-0 band of the $4 \mathrm{p} \pi^{1} \Sigma_{\mathrm{u}}{ }^{+}$ $-\mathrm{b}^{1} \Sigma_{\mathrm{g}}{ }^{+}$transition has also been discussed by Lewis et al[49] who identified a small $\left(0.35 \mathrm{~cm}^{-1}\right)$ local perturbation affecting only $J^{\prime}=13$, that they suggested was due to interaction with the $\mathrm{f}^{1} \Sigma_{\mathrm{u}}{ }^{+}$valence state, possibly $\mathrm{v}^{\prime}=17$. The interaction is small, since the valence state has a rather longer bond length than the Rydberg state, leading to rather small overlap integrals.

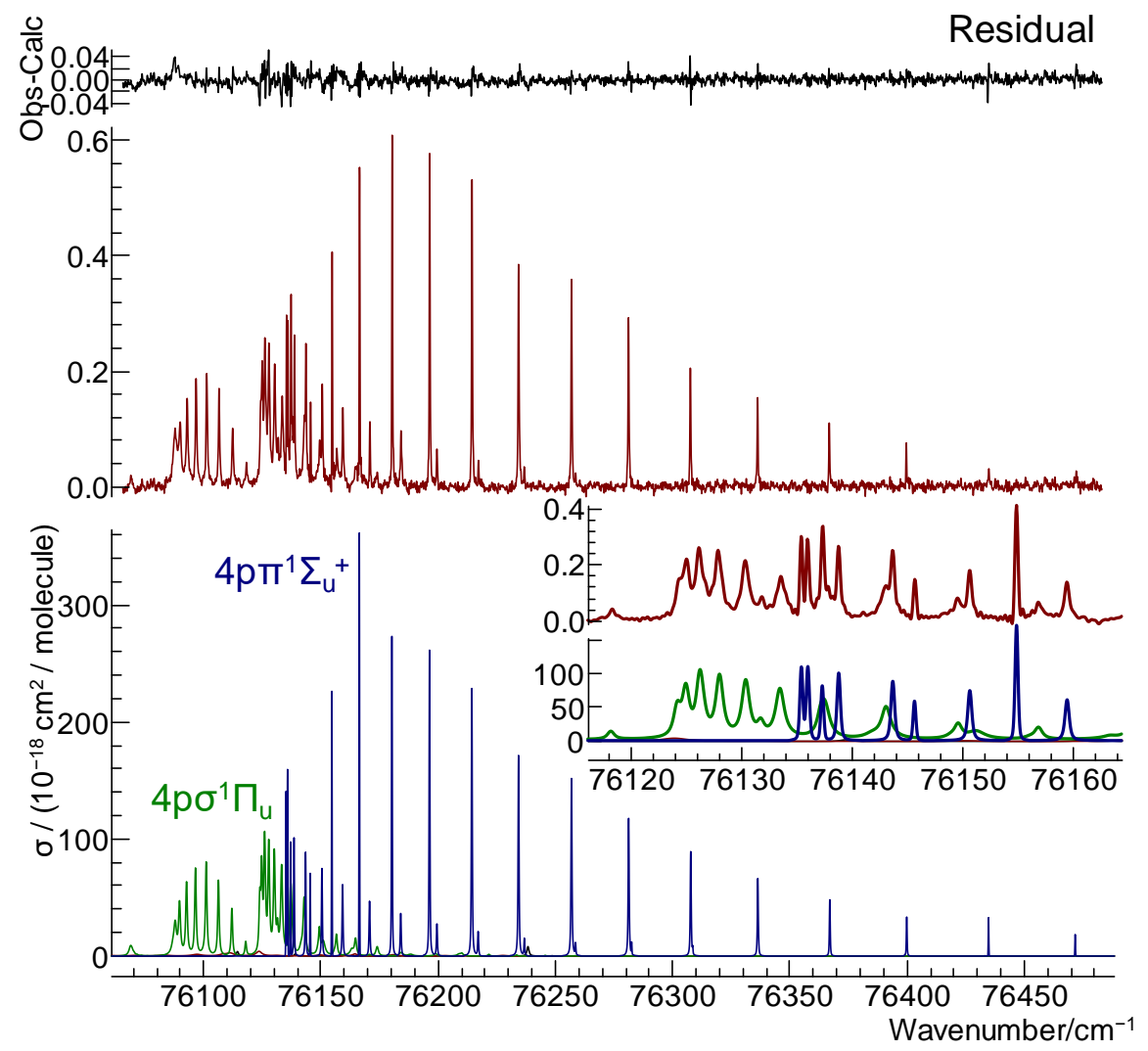

Figure 4. Experimental (middle trace), simulated (lower trace) spectra of the overlapping 1-0 bands of the $4 \mathrm{p} \pi^{1} \Sigma_{\mathrm{u}}{ }^{+}-\mathrm{b}^{1} \Sigma_{\mathrm{g}}{ }^{+}$(shown in blue in the lower trace) and $4 \mathrm{p} \sigma^{1} \Pi_{\mathrm{u}}-\mathrm{b}^{1} \Sigma_{\mathrm{g}}{ }^{+}$transitions (the broader lines, shown in green in the lower trace). The inset shows the central part of the spectrum and shows the difference in linewidth between the $4 \mathrm{p} \pi^{1} \Sigma_{\mathrm{u}}{ }^{+}$and $4 \mathrm{p} \sigma^{1} \Pi_{\mathrm{u}}$ states.

Our spectrum of this band (Figure 4) shows clear rotational structure, with a variety of widths distinguishable in the spectrum. Assignment of this band, based on the previous work, is straightforward, and is assisted by the observation that the transitions to the $4 p \sigma^{1} \Pi_{u}$ state are broader than to the $4 \mathrm{p} \pi^{1} \Sigma_{\mathrm{u}}{ }^{+}$state. The widths of the $4 \mathrm{p} \pi^{1} \Sigma_{\mathrm{u}}{ }^{+}$state in fact show a reasonably smooth trend with $J$, shown in Figure 5 as measured by fitting individual line profiles. The widths for the $4 \mathrm{p} \sigma^{1} \Pi_{\mathrm{u}}$ are broader, with a less pronounced trend with $J$. 


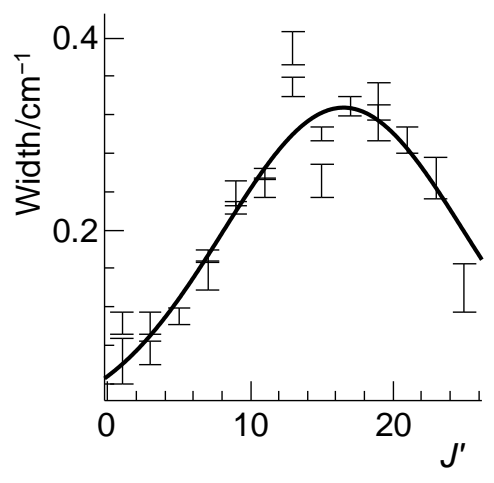

Figure 5 Lorentzian component of the widths of transitions to the $4 \mathrm{p} \pi^{1} \Sigma_{\mathrm{u}}{ }^{+}(\mathrm{v}=1)$ state of $\mathrm{O}_{2}$ as a function of the upper state $J$. Error bars are \pm one standard deviation. The solid curve is a plot of the model discussed in the text.

Given the previous work, it is clear that a full model including perturbations is required. Initially the interactions between states was ignored, and a simple line position fit was performed for the transitions to the $4 \mathrm{p} \pi^{1} \Sigma_{\mathrm{u}}{ }^{+}, 4 \mathrm{p} \sigma^{1} \Pi_{\mathrm{u}}$ and $4 \mathrm{p} \pi^{1} \Delta_{\mathrm{u}}$ states measured here, as well as to the line positions given in [19] [20] and [24], including transitions from the $\mathrm{a}^{1} \Delta_{\mathrm{g}}$ state. The $4 \mathrm{p} \sigma^{1} \Pi_{\mathrm{u}}-\mathrm{a}^{1} \Delta_{\mathrm{g}}(1-0)$ transition was visible at $122.91 \mathrm{~nm}$ and the measured line positions were also included in the fit. The $4 \mathrm{p} \pi^{1} \Delta_{\mathrm{u}}-\mathrm{a}^{1} \Delta_{\mathrm{g}} 1-0$ band was only tentatively visible in our spectra, though Yamawaki[24] was able to determine some line positions for this band. Our line positions and assignments are essentially consistent with previous work, though again more accurate. This simple fit confirmed the presence of interactions between states, and also that $J^{\prime}=13$ of the $4 \mathrm{p} \pi^{1} \Sigma_{\mathrm{u}}{ }^{+}$state was indeed subject to a local perturbation. (This is also visible in Figure 5 as a slightly higher width for $J^{\prime}=13$.) The model was then refined by adding heterogeneous $\left(\hat{J}_{+} \hat{L}_{\mp}\right)$ perturbations between the interacting states. While a good fit was obtained by including a homogeneous interaction between the $\mathrm{f}^{1} \Sigma_{\mathrm{u}}{ }^{+}$and $4 \mathrm{p} \pi^{1} \Sigma_{\mathrm{u}}{ }^{+}$states as suggested by Lewis et al[49], a slightly better fit was obtained by adding a heterogeneous interaction between the $\mathrm{f}^{1} \Sigma_{\mathrm{u}}^{+}$and $4 \mathrm{p} \sigma^{1} \Pi_{\mathrm{u}}$ states. Our data does not provide much discrimination between the two models, both of which can account for the shift of the $J^{\prime}=13$ level, though the difference between the rotational constants is smaller if the $4 \mathrm{p} \sigma^{1} \Pi_{\mathrm{u}}$ is involved, making it likely to be the stronger interaction. The final constants from a line position fit are given in Table 9.

Given the mixing between the $4 p \pi^{1} \Sigma_{u}{ }^{+}$and $4 p \sigma^{1} \Pi_{u}$ states, the transition dipole moment of the $4 p \sigma^{1} \Pi_{\mathrm{u}}-\mathrm{b}^{1} \Sigma_{\mathrm{g}}{ }^{+}$transition (which makes a significant contribution to the observed spectrum) is required for quantitative modelling. This was determined by a band contour fit to the experimental spectrum with the PGOPHER program[46], rather than by fitting to measurements of individual line intensities. Note that the relative signs of the transition moments to the $4 \mathrm{p} \pi^{1} \Sigma_{\mathrm{u}}{ }^{+}$and $4 \mathrm{p} \sigma^{1} \Pi_{\mathrm{u}}$ states are important; simulations show clearly that they must have the same sign; if they had opposite sign there would be significant cancelation of intensity, and the branch at longest wavelength would almost vanish. We assume that the intensity of transitions to the $\mathrm{f}^{1} \Sigma_{\mathrm{u}}{ }^{+}$state is negligible, and that the $4 \mathrm{p} \pi^{1} \Delta_{\mathrm{u}}-\mathrm{b}^{1} \Sigma_{\mathrm{g}}{ }^{+}$transition is forbidden.

Fitting directly to the experimental spectrum also requires a model for the statedependent linewidths arising from predissociation. For this, a width is assigned to each state, and then the width of each rotational level is calculated based on the (rotational-level dependent) degree of mixing between the states. For the $4 \mathrm{p} \pi^{1} \Sigma_{\mathrm{u}}{ }^{+}$state an empirical formula for the width was used: 


$$
w=a \exp \left(-b\left(J-J_{\max }\right)^{2}\right)
$$

with the form simply chosen as that giving a maximum with sensible limiting values. This probably arises from $J$-dependent mixing with at least one other state not included in our model. For the other states, the width was assumed to be rotational-level independent (implying a homogeneous predissociation mechanism). The widths were then determined by a direct fit to the experimental intensities, and the $4 \mathrm{p} \sigma^{1} \Pi_{\mathrm{u}}-\mathrm{b}^{1} \Sigma_{\mathrm{g}}{ }^{+}$transition moment was also derived by fitting, with the $4 \mathrm{p} \pi^{1} \Sigma_{\mathrm{u}}{ }^{+}-\mathrm{b}^{1} \Sigma_{\mathrm{g}}{ }^{+}$transition moment set to our ab initio value. As this gives a better model of blends, selected rotational constants were also included in this fit, though there is not enough information in our spectrum to determine all of them from the contour fit. The constants for the $4 \mathrm{p} \pi^{1} \Delta_{\mathrm{u}}$ state were therefore fixed to the values obtained from the line position fit. A width of $5 \mathrm{~cm}^{-1}$ was estimated for this state, based on the minimum separation of the lines observed by Yamawaki[24]. A width of $1 \mathrm{~cm}^{-1}$ was taken for the $\mathrm{f}^{1} \Sigma_{\mathrm{u}}{ }^{+}$state; there is no independent information on this width, though a value of zero leads to the prediction of an (unobserved) additional sharp transition to this state becoming visible, whereas a value of 1 $\mathrm{cm}^{-1}$ or more reduces the peak intensity below the noise level.

The parameters from the contour fit are given in the last column of Table 9, and Figure 4 shows the resulting simulation of the centre of the band, together with the experimental spectrum. The fit is good, with maximum errors $10 \%$ of the maximal intensities, with only the band head at $76090 \mathrm{~cm}^{-1}$ showing any sign of a systematic error. This could easily arise from an imperfect model of the three-way interaction between the $4 \mathrm{p} \sigma^{1} \Pi_{\mathrm{u}}, 4 \mathrm{p} \pi^{1} \Delta_{\mathrm{u}}$ and $\mathrm{f}^{1} \Sigma_{\mathrm{u}}{ }^{+}$states, but we do not have enough information to refine this further. It does suggest that the sharp lines in the central region of the spectrum (around $76180 \mathrm{~cm}^{-1}$ ) would be the most reliable for $\mathrm{b}^{1} \Sigma_{\mathrm{g}}{ }^{+}$ state number density measurements.

A significant question is why the additional transitions and perturbations are not required to model the $0-0$ band, as the same corresponding set of states would be expected to occur in similar positions. However the observations of England et al[26] suggest that the $4 p \sigma^{1} \Pi_{\mathrm{u}} \mathrm{v}=0$ and $4 \mathrm{p} \pi^{1} \Delta_{\mathrm{u}} \mathrm{v}=0$ states are sufficiently far below $4 \mathrm{p} \pi^{1} \Sigma_{\mathrm{u}}{ }^{+} \mathrm{v}^{\prime}=0$ to prevent significant state mixing. We would also expect transitions from $\mathrm{v}=0$ of the $\mathrm{a}^{1} \Delta_{\mathrm{g}}$ state to $\mathrm{v}=0$ of the $4 p \sigma^{1} \Pi_{\mathrm{u}}$ and $4 \mathrm{p} \pi^{1} \Delta_{\mathrm{u}}$ states to occur around $126 \mathrm{~nm}$, and these transitions have been assigned by Yamawaki[24] to bands he observed at 126.30 and $126.26 \mathrm{~nm}$. These peaks are also visible in our spectra, and a tentative analysis is presented below, confirming the approximate location of these states and justifying their exclusion from the $4 \mathrm{p} \pi^{1} \Sigma_{\mathrm{u}}{ }^{+} \mathrm{v}^{\prime}=0$ analysis.

As a quality check on the transition dipole moments for the 0-0 and 1-0 transitions obtained from our $a b$ initio calculations, the overall intensity scale factors, $I_{s}$, and temperatures, $T$, determined from fitting to experimental spectra recorded under the same conditions can be compared. Both are reasonably consistent; the $0-0$ band has $I_{s}=2.32 \pm 0.03$ and $T=321 \pm 2 \mathrm{~K}$ and the 1-0 band has $I_{s}=2.30 \pm 0.01$ and $T=348 \pm 2 \mathrm{~K}$ for the spectra in Figure 3 and Figure 4. This consistency confirms that the rotational model for both states is good, and that no significant local interactions with other states have been omitted. This implies that the relative values of the 0-0 and 1-0 transition moments are good; validation of the absolute values requires comparison with an independent determination. The fact that the bands are both fully rotationally-resolved and well-fitted indicates that our model of the state is close to complete, and that any missing interactions are unlikely to significantly affect the intensities.

Table 9 Rotational Parameters ${ }^{\mathrm{a}}\left(/ \mathrm{cm}^{-1}\right)$ of $\mathrm{v}=1$ of the $4 \mathrm{p} \pi^{1} \Sigma_{\mathrm{u}}{ }^{+}$state of $\mathrm{O}_{2}$

\begin{tabular}{|l|l|l|l|}
\hline & & Line Position Fit & Band Contour Fit \\
\hline $4 \mathrm{p} \pi^{1} \Sigma_{\mathrm{u}}{ }^{+} \mathrm{v}=1$ & Origin $^{\mathrm{b}}$ & $89264.197(37)$ & $89264.123(2)$ \\
\hline
\end{tabular}




\begin{tabular}{|c|c|c|c|}
\hline & $B$ & $1.67193(45)$ & $1.67293(4)$ \\
\hline & $D \times 10^{6}$ & $7.70(45)$ & $9.68(5)$ \\
\hline & $a^{\mathrm{c}}$ & & $0.327(4)$ \\
\hline & $b \times 10^{3 \mathrm{c}}$ & & $7.7(2)$ \\
\hline & $J_{\max }{ }^{\mathrm{c}}$ & & $16.1(2)$ \\
\hline \multirow[t]{4}{*}{$4 p \sigma^{1} \Pi_{u} v=1$} & Origin $^{b}$ & $89245.886(28)$ & $89245.860(5)$ \\
\hline & $B$ & $1.43661(37)$ & $1.43584(7)$ \\
\hline & $q \times 10^{3}$ & $-3.42(82)$ & $-1.58(10)$ \\
\hline & Width & & $0.658(7)$ \\
\hline$\left.<4 \mathrm{p} \pi^{1} \Sigma_{\mathrm{u}}{ }^{+} \mathrm{v}=1\left|J_{+} L_{-}\right| 4 \mathrm{p} \sigma^{1} \Pi_{\mathrm{u}} \mathrm{v}=1\right\rangle$ & & $0.9808(78)$ & $0.9842(6)$ \\
\hline \multirow[t]{3}{*}{$4 \mathrm{p} \pi^{1} \Delta_{\mathrm{u}} \mathrm{V}=1$} & Origin $^{\mathrm{b}}$ & $89153.95(14)$ & $\mathrm{d}$ \\
\hline & $B$ & $1.6548(19)$ & $\mathrm{d}$ \\
\hline & Width & & $5.0^{\mathrm{e}}$ \\
\hline$<4 \mathrm{p} \pi^{1} \Delta_{\mathrm{u}} \mathrm{v}=1\left|J_{+} L_{-}\right| 4 \mathrm{p} \sigma^{1} \Pi_{\mathrm{u}} \mathrm{v}=1>$ & & $0.923(13)$ & $0.966(2)$ \\
\hline \multirow[t]{3}{*}{$\mathrm{f}^{1} \Sigma_{\mathrm{u}}^{+} \mathrm{v}=17(?)$} & Origin $^{\mathrm{b}}$ & $89406.7(114)$ & $89383.4(3)$ \\
\hline & $B$ & $0.9994(299)$ & $1.059(1)$ \\
\hline & Width & & 1 \\
\hline$\left\langle\mathrm{f}^{1} \Sigma_{\mathrm{u}}{ }^{+} \mathrm{v}=17(?) \| 4 \mathrm{p} \pi^{1} \Sigma_{\mathrm{u}}{ }^{+} \mathrm{v}=1\right\rangle$ & & $-0.56(22)$ & $-1.40(2)$ \\
\hline$\left\langle\mathrm{f}^{1} \Sigma_{\mathrm{u}}{ }^{+} \mathrm{v}=17(?)\left|J_{+} L-\right| 4 \mathrm{p} \sigma^{1} \Pi_{\mathrm{u}} \mathrm{v}=1\right\rangle$ & & $0.433(27)$ & $0.452(4)$ \\
\hline$\left.<4 p \pi^{1} \Sigma_{\mathrm{u}}{ }^{+} \mathrm{v}=1|\mu| \mathrm{b}^{1} \Sigma_{\mathrm{g}}{ }^{+} \mathrm{v}=0\right\rangle$ & & & -0.211 \\
\hline$\left\langle 4 p \sigma^{1} \Pi_{\mathrm{u}} \mathrm{v}=1|\mu| \mathrm{b}^{1} \Sigma_{\mathrm{g}}{ }^{+} \mathrm{v}=0\right\rangle$ & & & $-0.1642(6)$ \\
\hline$N_{\text {obs }}$ & & 216 & \\
\hline$\sigma$ & & 0.12 & \\
\hline
\end{tabular}

${ }^{\text {a }}$ Figures in parentheses are standard deviations in units of the last significant figure.

${ }^{\mathrm{b}}$ Relative to the $J=0, \mathrm{v}=0$ level of the $\mathrm{X}^{3} \Sigma_{\mathrm{g}}{ }^{-}$state.

${ }^{c}$ Width of an individual (unmixed) state is $a \exp \left(-b\left(J-J_{\max }\right)^{2}\right)$

${ }^{\mathrm{d}}$ Constrained to value for line position fit.

${ }^{\mathrm{e}}$ Fixed

\section{Rotational analysis of the $3 p \pi^{1} \Sigma_{u}{ }^{+}-b^{1} \Sigma_{g}{ }^{+}$transition}

Transitions to the $3 \mathrm{p} \pi^{1} \Sigma_{\mathrm{u}}{ }^{+}$Rydberg state from the $\mathrm{b}^{1} \Sigma_{\mathrm{g}}{ }^{+}$state are observed in the experimental spectra as a clear progression of structured bands, extending from the origin band at $158.39 \mathrm{~nm}$ to the $4-0$ band at $141.91 \mathrm{~nm}$. Given that these are in the region of the strong $\mathrm{O}_{2}$ ground state continuum, they are only of limited use for probing $b$ state concentrations, but they do serve as an additional check as to the quality of the ab initio calculations as they show clearly in our spectra. These bands have been analysed by Katayama et al[19], and the results presented here are consistent with their work, though our Fourier transform spectra give better results, particularly with respect to line width measurements. All the bands show clear rotational structure, with linewidths depending on both $J^{\prime}$ and $\mathrm{v}^{\prime}$. The bands were fitted using the same band contour fitting methodology as for the $4 \mathrm{p} \pi^{1} \Sigma_{\mathrm{u}}{ }^{+}$state above. Most show overlapping absorptions from $\mathrm{CO}$, clearly distinguishable by the sharper lines; as above these $\mathrm{CO}$ bands were also fitted to allow inclusion in the band contour fits. The linewidth was taken to be of the form $w=k_{0}+k_{J} J(J+1)$. This is consistent with a heterogeneous mixing with another state, perhaps the $3 p \sigma^{1} \Pi_{\mathrm{u}}$ state. Apart from $\mathrm{v}^{\prime}=2$, where there is a large width even for the lowest $J$, there is a clear trend with $J$. For $\mathrm{v}^{\prime}=4$ our observations confirmed the observation by Katayama et al[19] of a localised perturbation around $J^{\prime}=10$; the localised nature of the perturbation suggests a $J$ dependent perturbation, implying the perturbing state has $\Omega=1$. We modelled this by including a ${ }^{1} \Pi_{u}$ state in the Hamiltonian matrix, with parameters given in 
Table 10. However, since there is no direct information on the perturbing state, other possible state types, including triplet states, could give a fit of similar quality. The mixing with the perturbing state is sufficiently strong that some transitions to it should be visible, even in the absence of any intrinsic intensity. The absence of any such transitions implies a width to the perturbing state of at least $10 \mathrm{~cm}^{-1}$, which would lead to the intensity of the broadened peaks being comparable to the noise level. For $\mathrm{v}^{\prime}=0$ a small systematic intensity error was observed in the initial fits, which could be modelled by including a mild $J^{\prime}$ dependence of the rotational transition moment; this is the (dimensionless) $A_{1}$ parameter in Table 10, using the definition given by Watson[45]. The final constants are given in Table 10, and the experimental spectra and simulations are shown in Figure 6. This table contains the results of two fits for all but $\mathrm{v}^{\prime}=4$; these are independent fits to separately recorded spectra which is required for the following discussion of relative intensities. The results should be identical within the true error bars, and the values shown further demonstrates the need to scale up the raw standard deviations given by the fitting process.

In order to test the transition dipole moments, a relative concentration is given in the table, essentially the vertical scaling factor needed for the least squares fit. The requirement for multiple fits arises because the $\mathrm{v}=0$ and 4 bands were not recorded on the same spectrum as the other three. A corrected concentration is then included in the table, derived by requiring the scale factors on overlapping spectra to match. These should all be identical if the transition dipole moments are correct, and they actually show a similar level of consistency to the $3 \mathrm{p} \pi^{1} \Delta_{\mathrm{u}}$ $-\mathrm{a}^{1} \Delta_{\mathrm{g}}$ transition discussed above, confirming our model for these states, even though the $\mathrm{v}^{\prime}=4$ state is a little out of line.

Table 10 Rotational Parameters ${ }^{\mathrm{a}}\left(/ \mathrm{cm}^{-1}\right)$ of the $3 \mathrm{p} \pi^{1} \Sigma_{\mathrm{u}}^{+}$state of $\mathrm{O}_{2}$

\begin{tabular}{|c|c|c|c|c|c|c|c|c|c|}
\hline $\mathrm{v}^{\mathrm{b}}$ & Origin $^{c}$ & $B$ & $D \times 10^{6}$ & $k_{0}$ & $k_{J} \times 10^{3}$ & $A_{1} \times 10^{3}$ & $\begin{array}{c}\text { Relative } \\
\text { Concentration }\end{array}$ & $\begin{array}{l}\text { Spectrum } \\
\text { ID }\end{array}$ & $\begin{array}{c}\text { Corrected } \\
\text { Concentration }\end{array}$ \\
\hline \multirow{2}{*}{0} & $76263.4765(22)$ & $1.693300(46)$ & $5.36(16)$ & $0.1778(76)$ & $3.120(56)$ & $-5.00(17)$ & $44.45(25)$ & $545 \mathrm{~A}$ & \multirow{2}{*}{$4.886(48)$} \\
\hline & $76263.4635(15)$ & $1.693582(32)$ & $6.16(13)$ & $0.1946(41)$ & $2.347(38)$ & $-3.79(13)$ & $16.942(69)$ & $533 \mathrm{~A}$ & \\
\hline \multirow{2}{*}{1} & $78152.5824(23)$ & $1.674484(50)$ & $5.04(20)$ & $0.6314(98)$ & $6.132(66)$ & $0^{\mathrm{d}}$ & $16.960(38)$ & $533 \mathrm{~A}$ & \multirow{2}{*}{$4.892(43)$} \\
\hline & $78152.5969(88)$ & $1.67459(19)$ & $5.06(83)$ & $0.669(36)$ & $5.19(26)$ & $0^{\mathrm{d}}$ & $4.892(43)$ & $520 \mathrm{~A}$ & \\
\hline \multirow{2}{*}{2} & $80002.236(28)$ & $1.65002(33)$ & $6.09^{\mathrm{d}}$ & $3.997(55)$ & $10.10^{\mathrm{d}}$ & $0^{\mathrm{d}}$ & $4.724(42)$ & $520 \mathrm{~A}$ & $4.724(42)$ \\
\hline & $80002.2200(81)$ & $1.65048(15)$ & $6.09(44)$ & $4.226(21)$ & $10.10(21)$ & $0^{\mathrm{d}}$ & f & & \\
\hline \multirow{2}{*}{3} & $81823.7737(95)$ & $1.63172(11)$ & $0^{\mathrm{d}}$ & $0.897(24)$ & $6.94(26)$ & $0^{\mathrm{d}}$ & $5.493(40)$ & $520 \mathrm{~A}$ & \multirow{2}{*}{$5.493(40)$} \\
\hline & $81823.728(12)$ & $1.63194(14)$ & $0^{\mathrm{d}}$ & $1.105(31)$ & $7.97(35)$ & $0^{\mathrm{d}}$ & $7.924(85)$ & $504 \mathrm{~A}$ & \\
\hline 4 & $83600.8926(52)$ & $1.60851(21)$ & $9.53(90)$ & $0.1538(87)$ & $6.70(17)$ & $0^{\mathrm{d}}$ & $10.37(11)$ & $504 \mathrm{~A}$ & $7.19(11)$ \\
\hline${ }^{1} \Pi^{\mathrm{e}}$ & $83641.33(287)$ & $1.2002(279)$ & $0^{\mathrm{d}}$ & $10^{\mathrm{d}}$ & $0^{\mathrm{d}}$ & $0^{\mathrm{d}}$ & & $504 \mathrm{~A}$ & \\
\hline
\end{tabular}

${ }^{a}$ Figures in parentheses are standard deviations in units of the last significant figure; as discussed in the text these probably should be scaled up by at least 5 .

${ }^{b}$ Two independent fits to separate spectra are given for $v^{\prime}=0$ to 3

${ }^{\mathrm{c}}$ Relative to the $J=0, \mathrm{v}=0$ level of the $\mathrm{X}^{3} \Sigma_{\mathrm{g}}{ }^{-}$state.

${ }^{\mathrm{d}}$ Fixed

${ }^{\mathrm{e}}$ State perturbing $\mathrm{v}=4$, matrix elements:

$<3 \mathrm{p} \pi^{1} \Sigma_{\mathrm{u}}{ }^{+} \mathrm{v}=4\left|J_{+} L-\right|^{1} \Pi_{\mathrm{u}}>=0.2693(82) \sqrt{2 J(J+1)} \mathrm{cm}^{-1}$.

${ }^{\mathrm{f}}$ From spectrum recorded out of sequence with better signal to noise 

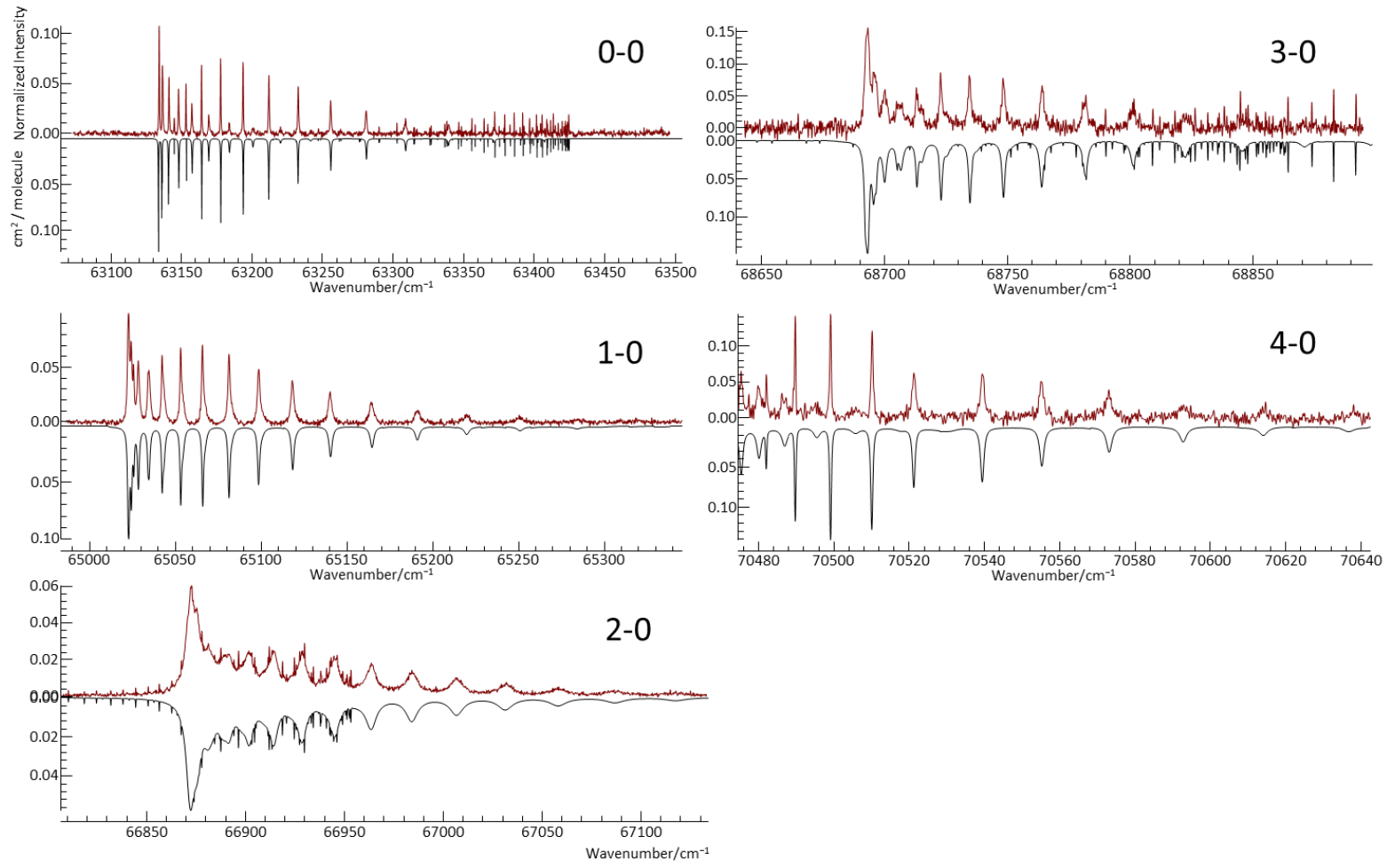

Figure 6 Experimental measurements (Upper plots) simulations (inverted lower plots) of five vibrational bands of the $3 \mathrm{p} \pi^{1} \Sigma_{\mathrm{u}}{ }^{+}-\mathrm{b}^{1} \Sigma_{\mathrm{g}}{ }^{+}$transition in $\mathrm{O}_{2}$. The weaker sharp lines present in all plots apart from the 1-0 band are various bands of the A-X transition in CO.

\section{Other States}

$3 p \sigma^{1} \Pi$

A diffuse band observed at $161.118 \mathrm{~nm}$, shown in Figure 7, was not specifically assigned by Katayama et al[19], though they tentatively identified it as ${ }^{1} \Pi-\mathrm{b}^{1} \Sigma_{\mathrm{g}}{ }^{+}$, and noted that it has no isotope shift. Given that it is only $1025 \mathrm{~cm}^{-1}$ below the $3 \mathrm{p} \pi^{1} \Sigma_{\mathrm{u}}{ }^{+}-\mathrm{b}^{1} \Sigma_{\mathrm{g}}{ }^{+}$origin, the implication is that it is most likely the origin band of the $3 p \sigma^{1} \Pi_{\mathrm{u}}-\mathrm{b}^{1} \Sigma_{\mathrm{g}}{ }^{+}$transition, and this conclusion was also reached by an optical-optical double resonance study[22]. The $3 \mathrm{p} \pi^{1} \Sigma_{\mathrm{u}}{ }^{+}$ state should also be visible though the $3 \mathrm{p} \pi^{1} \Sigma_{\mathrm{u}}{ }^{+}-\mathrm{a}^{1} \Delta_{\mathrm{g}}$ transition, and indeed was observed at $148.64 \mathrm{~nm}$ in Figure 2. Table 11 gives the parameters determined from a contour fit to the spectrum given in Figure 2. Note that for this band it was necessary to include a $J$ dependence to the dipole moment (the dimensionless $A_{l}$ parameter used above). The same parameters give the simulated spectrum in Figure 7, with the only adjustment being to the transition dipole moment; a value of $\left\langle 3 p \sigma^{1} \Pi_{\mathrm{u}}{ }^{+} \mathrm{v}=0|\mu| \mathrm{b}^{1} \Sigma_{\mathrm{g}}{ }^{+} \mathrm{v}=0\right\rangle=0.2169(6)$ Debye was derived by comparison to the nearby $3 \mathrm{p} \pi^{1} \Sigma_{\mathrm{u}}{ }^{+}-\mathrm{b}^{1} \Sigma_{\mathrm{g}}{ }^{+} 0-0$ band, and a $J$ dependence to this transition moment with $A_{1}=-0.0564(8)$ improved the fit.

No other bands involving the $3 \mathrm{p} \sigma^{1} \Pi_{\mathrm{u}}$ state have been observed by previous workers, but we did see a band at $70763 \mathrm{~cm}^{-1}(141.3 \mathrm{~nm})$, visible in Figure 2, that is a good fit for the 2-0 band of the $3 p \sigma^{1} \Pi_{\mathrm{u}}-\mathrm{a}^{1} \Delta_{\mathrm{g}}$ transition, and parameters for this are given in Table 11. The matching $3 p \sigma^{1} \Pi_{\mathrm{u}}-\mathrm{b}^{1} \Sigma_{\mathrm{g}}{ }^{+}$2-0 band is not visible in our spectra. There is some evidence for a transition involving $v^{\prime}=1$ of the $3 p \sigma^{1} \Pi_{u}$ state; there is a rather weak broad feature in approximately the right place $\left(68710 \mathrm{~cm}^{-1}\right)$ in the middle of Figure 2, although the profile is not clean and it may include some baseline artefacts. Approximate parameters are included in Table 11 for this band. 


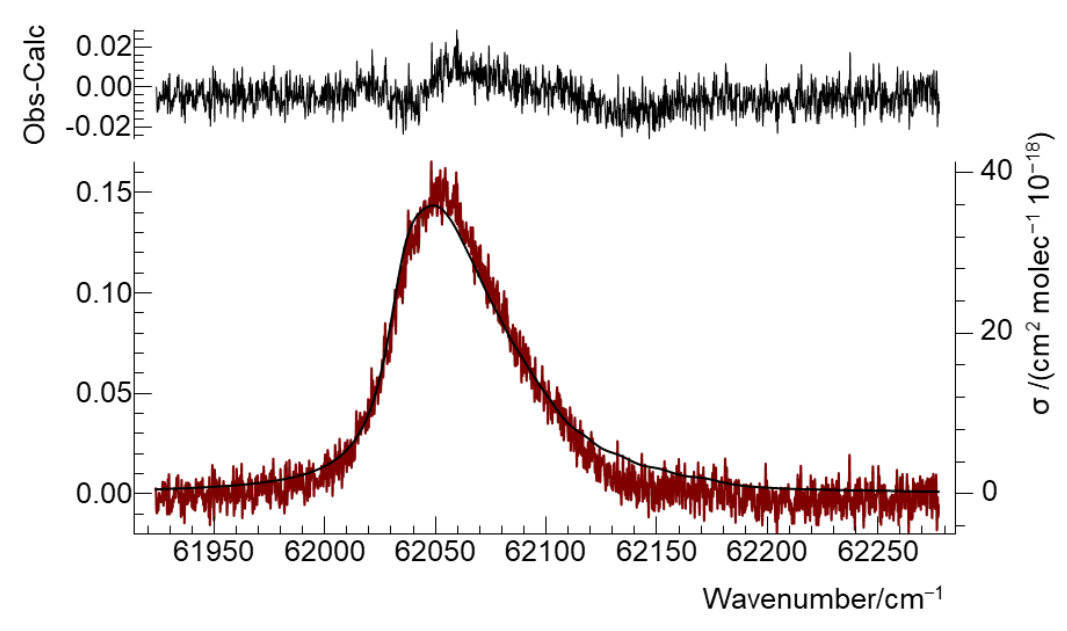

Figure 7 Spectrum of the $0-0$ band of the $3 p \sigma^{1} \Pi_{u}-b^{1} \Sigma_{g}{ }^{+}$transition at $161.118 \mathrm{~nm}$ The lower traces are the observed spectra (thin red lines, left axis) and simulations (thin black line) using the parameters given in Table 11. The right hand scale gives the simulated cross section.

Table 11 Parameters ${ }^{\mathrm{a}}\left(/ \mathrm{cm}^{-1}\right)$ for the $3 \mathrm{p} \sigma^{1} \Pi_{\mathrm{u}}$ state of $\mathrm{O}_{2}$

\begin{tabular}{|l|l|l|l|l|l|l|}
\hline & Origin $^{\mathrm{b}}$ & $B$ & $k_{0}$ & $k_{J}$ & $A_{1} \times 10^{-3}$ & $\mu^{\mathrm{c}} /$ Debye \\
\hline $\mathrm{v}=0$ & $75167.5(2)$ & $1.598(3)$ & $21.2(2)$ & 0 & $-17.0(6)$ & $0.3742(6)$ \\
\hline $\mathrm{v}=1^{\mathrm{d}}$ & 76549 & 1.598 & 215 & 0 & & 0.317 \\
\hline $\mathrm{v}=2$ & $78650.4(4)$ & $1.55(1)$ & $17.7(9)$ & $0.52(4)$ & & $0.241(2)$ \\
\hline
\end{tabular}

${ }^{a}$ Figures in parentheses are standard deviations in units of the last significant figure; as discussed in the text these should probably be scaled up by at least 5 .

${ }^{\mathrm{b}}$ Relative to the $J=0, \mathrm{v}=0$ level of the $\mathrm{X}^{3} \Sigma_{\mathrm{g}}{ }^{-}$state.

${ }^{c}$ Transition dipole $\left\langle 3 p \sigma^{1} \Pi_{\mathrm{u}} \mathrm{v}|\mu| \mathrm{b}^{1} \sum_{\mathrm{g}}{ }^{+} \mathrm{v}=0\right\rangle$ assuming $\left\langle 3 \mathrm{p} \pi^{1} \Delta_{\mathrm{u}} \mathrm{v}=1|\mu| \mathrm{b}^{1} \Sigma_{\mathrm{g}}{ }^{+} \mathrm{v}=0\right\rangle$ as given in Table 5.

d Tentative assignment

\section{$4 p \sigma^{1} \Pi_{u} v=0$ and $4 p \pi^{1} \Delta_{u} v=0$}

Yamawaki[24] suggested that the bands observed at 126.30 and $126.26 \mathrm{~nm}$ were due to transitions to ${ }^{1} \Pi_{\mathrm{u}}$ and ${ }^{1} \Delta_{\mathrm{u}}$ states from $\mathrm{a}^{1} \Delta_{\mathrm{g}}$, and the work of England et al[26] suggests they are the $4 \mathrm{p} \sigma^{1} \Pi_{\mathrm{u}}$ and $4 \mathrm{p} \pi^{1} \Delta_{\mathrm{u}} \mathrm{v}=0$ states respectively. Under the right conditions, our spectra show (Figure 8) at least two bands at $126.5 \mathrm{~nm}$. As discussed above, England et al[26] attributed their observed spectra around $87100 \mathrm{~cm}^{-1}$ to forbidden transitions from the ground $\mathrm{X}^{3} \Sigma_{\mathrm{g}}{ }^{-}$state, allowed by spin orbit mixing with an allowed $\mathrm{F}^{3} \Pi_{\mathrm{u}}-\mathrm{X}^{3} \Sigma_{\mathrm{g}}{ }^{-}$transition. They assigned the only three sharp features to $J^{\prime}=1$ of the $4 \mathrm{p} \pi^{1} \Pi_{\mathrm{u}} \mathrm{v}=0-\mathrm{X}^{3} \Sigma_{\mathrm{g}}{ }^{-}$transition, with all the other transitions being much broader, and assigned to strongly mixed nearly iso-energetic $4 p \sigma^{1} \Pi_{\mathrm{u}}$ and $4 \mathrm{p} \pi^{1} \Delta_{\mathrm{u}}$ $\mathrm{v}=0$ states, with the width originating from the $4 \mathrm{p} \pi^{1} \Delta_{\mathrm{u}} \mathrm{v}=0$ state. The previous work implied a state energy for the $J^{\prime}=1$ state of $87111.58 \mathrm{~cm}^{-1}$ with respect to $J^{\prime \prime}=0, \mathrm{v}=0$ of $\mathrm{X}^{3} \Sigma_{\mathrm{g}}{ }^{-}$. The only possible transition to $J^{\prime}=1$ of this state originating from a ${ }^{1} \Delta_{\mathrm{g}} \mathrm{V}=0$ would be from the $J^{\prime \prime}=2$ level at $7892.02 \mathrm{~cm}^{-1}$ implying a single transition at $79219.56 \mathrm{~cm}^{-1}$, and we indeed observe a sharp peak at $79219.78 \mathrm{~cm}^{-1}$, within the $0.2 \mathrm{~cm}^{-1}$ accuracy claimed by England et al[26]. However, we were not able to develop a simulation based on this, and the constants used for the $\mathrm{v}=1$ analysis. Transitions to both $4 \mathrm{p} \sigma^{1} \Pi_{\mathrm{u}}$ and $4 \mathrm{p} \pi^{1} \Delta_{\mathrm{u}}$ are expected from $\mathrm{a}^{1} \Delta_{\mathrm{g}}$, with a strong central Q branch for the $4 \mathrm{p} \sigma^{1} \Pi_{\mathrm{u}}$ state, and a blue degraded band for the $4 \mathrm{p} \pi^{1} \Delta_{\mathrm{u}}$ state. This suggests that the feature at $79205 \mathrm{~cm}^{-1}$ is the ${ }^{1} \Pi_{\mathrm{u}}$ state, with the ${ }^{1} \Delta_{\mathrm{u}}$ state underneath it. The head at $79020 \mathrm{~cm}^{-1}$ has a similar contour, implying another ${ }^{1} \Delta_{\mathrm{u}}$ state. This can be understood if the $4 \mathrm{p} \pi^{1} \Delta_{\mathrm{u}}$ and $4 \mathrm{p} \pi^{3} \Delta_{\mathrm{u}}$ states are close together in energy, and thus mixed by the 
spin-orbit coupling expected for such pairs of states[44]. The lower trace of Figure 8 shows a tentative simulation developed along these lines, with the parameters given in Table 12. The feature at the lowest frequency is the $\mathrm{E}^{3} \Sigma_{\mathrm{u}}{ }^{-}-\mathrm{X}^{3} \Sigma_{\mathrm{g}}{ }^{-} 0-1$ band, which we simulated using upper state constants from Lewis et al[50]. The singlet state constants must be regarded as estimates only; the fine detail in the spectrum is only partly reproduced, and the implied $J^{\prime}$ assignment could easily be off by at least 1 , and the sharp feature at $79219.78 \mathrm{~cm}^{-1}$ has been ignored. Attempts to model this spectrum based on the strong $\Pi-\Delta$ mixing suggested by England et al[26] were not successful; we cannot entirely discount that model but unfortunately it is not possible to refine the model further given the lack of quantum-state-specific information.

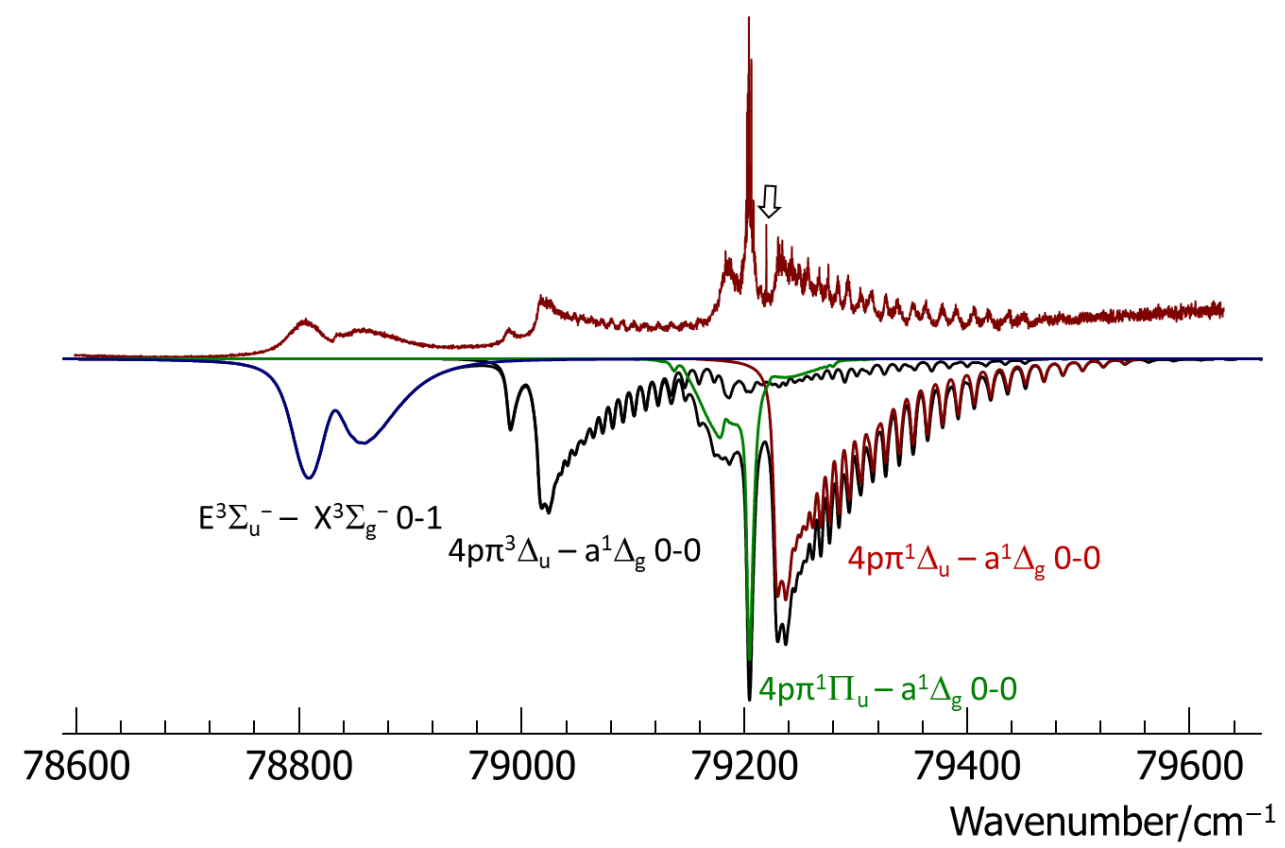

Figure 8 Spectrum of the $4 p \sigma^{1} \Pi_{u}$ and $4 p \pi^{1} \Delta_{u}-a^{1} \Delta_{g} 0-0$ bands. The upper trace is the observed spectrum, and the lower traces are simulations of the bands indicated, and a sum of all the bands. The arrow indicates the line discussed in the text.

Table 12 Parameters used for simulations of the $4 p \sigma^{1} \Pi_{\mathrm{u}}$ and $4 \mathrm{p} \pi^{1} \Delta_{\mathrm{u}}-\mathrm{a}^{1} \Delta_{\mathrm{g}} 0-0$ bands of $\mathrm{O}_{2}$

\begin{tabular}{|c|c|c|}
\hline & Parameter & Value $/ \mathrm{cm}^{-1}$ \\
\hline \multirow{4}{*}{$4 p \pi^{1} \Delta_{u} v=0$} & Origin $^{\mathrm{a}}$ & 87033.89 \\
\hline & $B$ & 1.8544 \\
\hline & $D \times 10^{6}$ & 204.6 \\
\hline & Width & 0 \\
\hline \multirow{5}{*}{$4 \mathrm{p} \pi^{3} \Delta_{\mathrm{u}} \mathrm{v}=0$} & Origin $^{\mathrm{a}}$ & 86985.54 \\
\hline & $A$ & 49.33 \\
\hline & $B$ & 1.6103 \\
\hline & $D \times 10^{6}$ & -111.2 \\
\hline & Width & 6 \\
\hline \multicolumn{2}{|c|}{$\left\langle 4 \mathrm{p} \pi^{1} \Delta_{2 \mathrm{u}} \mathrm{V}=0\left|\mathrm{H}_{\mathrm{so}}\right| 4 \mathrm{p} \pi^{3} \Delta_{2 \mathrm{u}} \mathrm{V}=0\right\rangle$} & 104.21 \\
\hline \multirow{3}{*}{$4 p \sigma^{1} \Pi_{u} v=0$} & Origin $^{\mathrm{a}}$ & 87086.6 \\
\hline & $B$ & 1.43 \\
\hline & $D \times 10^{6}$ & 0 \\
\hline \multicolumn{2}{|c|}{$<4 p \pi^{1} \Delta_{\mathrm{u}} \mathrm{v}=0|\mu| \mathrm{a}^{1} \Delta_{\mathrm{g}} \mathrm{v}=0>/$ Debye } & 0.2213 \\
\hline
\end{tabular}


\begin{tabular}{|l|l|}
\hline$<4 \mathrm{p} \sigma^{1} \Pi_{\mathrm{u}} \mathrm{v}=0|\mu| \mathrm{a}^{1} \Delta_{\mathrm{g}} \mathrm{v}=0>/$ Debye & 0.1 \\
\hline
\end{tabular}

${ }^{\text {a }}$ Relative to the $J=0, \mathrm{v}=0$ level of the $\mathrm{X}^{3} \Sigma_{\mathrm{g}}^{-}$state.

There is an additional ${ }^{1} \Delta-{ }^{1} \Delta$ transition around $124.4 \mathrm{~nm}$ that has not yet been discussed, shown in Figure 9. The band is clearly visible as a set of sharp features, on top of a broad feature, that vanish on removing the discharge. The broad features are known to arise from the origin band of the $\mathrm{E}^{3} \Sigma_{\mathrm{u}}{ }^{-}-\mathrm{X}^{3} \Sigma_{\mathrm{g}}^{-}$ground state absorption which has been modelled in detail by Lewis et al[50], who found that a $J$ dependent Fano lineshape is required to reproduce the observed spectrum. Unfortunately it is difficult to produce a clean spectrum of the sharp transition, as a simple subtraction does not give a clean result, presumably due a change in the $\mathrm{X}$ state density and temperature in the presence of the discharge. It is clear, however, that simulation as ${ }^{1} \Delta_{\mathrm{u}}-\mathrm{a}^{1} \Delta_{\mathrm{g}} \mathrm{v}=0$ gives good results, with the constants given in Table 13 from a line position fit. The linewidth is estimated at $0.5 \mathrm{~cm}^{-1}$, and there is some indication that higher $J$ lines have broader width, although the signal to noise is not sufficient to be more precise. This band has been observed previously[20,24], but the upper state was not assigned, and appears not to be part of a progression. The rotational constant is smaller than most of the Rydberg states (see Table 1) suggesting it has significant valence character. It may be that it results from a double minimum potential linked with the $4 \mathrm{p} \pi^{1} \Delta_{u}$ state, along the lines of that suggested by Lewis et al for the $4 \mathrm{p} \sigma^{1} \Pi_{\mathrm{u}}$ state (see figure 2 of ref[44]). Unfortunately, the required range of bond lengths is not covered by our $a b$ initio calculations, precisely because of valence states becoming important for this range, and this would require increasing the number of states beyond a manageable number.

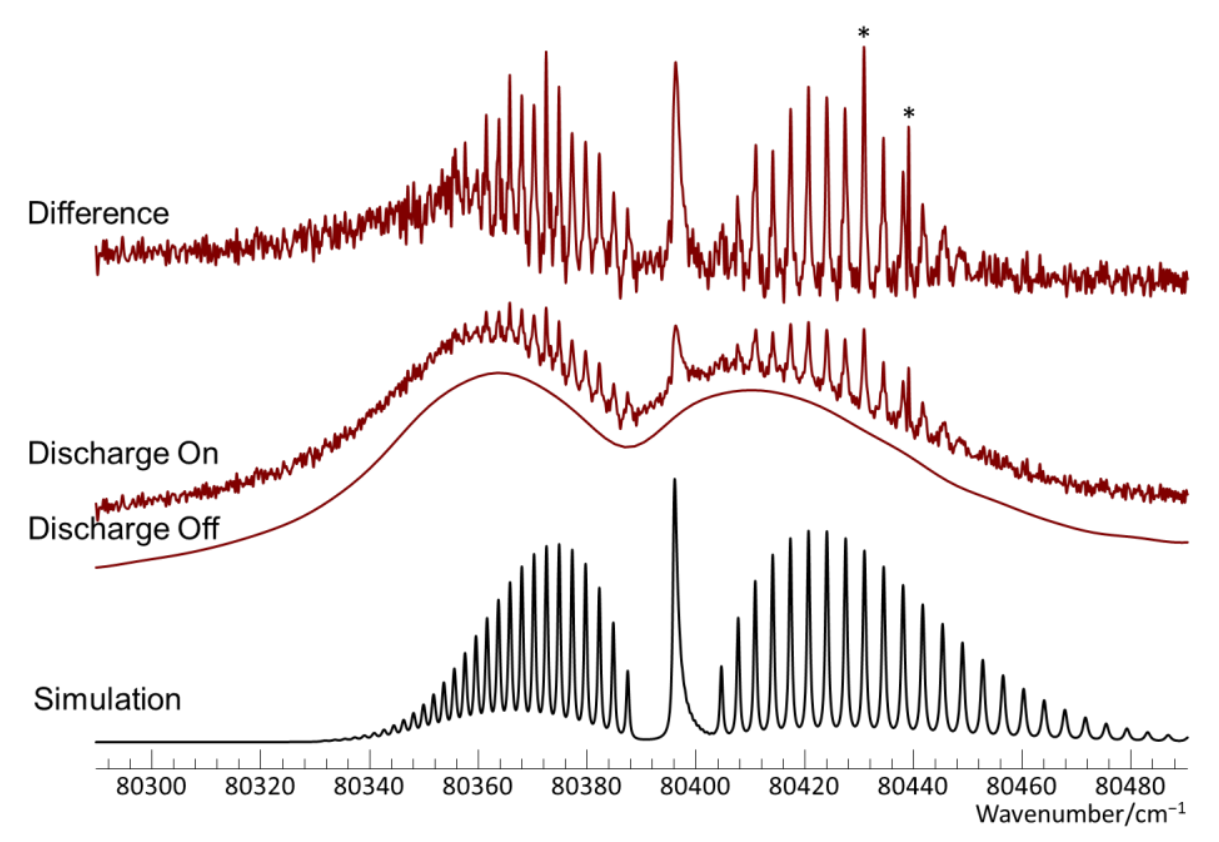

Figure 9 Region around the $\mathrm{E}^{3} \Sigma_{\mathrm{u}}{ }^{-}-\mathrm{X}^{3} \Sigma_{\mathrm{g}}{ }^{-}$0-0 transition at $124.4 \mathrm{~nm}$. The top trace is the difference between the next two traces, showing the spectrum with and without the discharge, and lower trace is the simulation of the ${ }^{1} \Delta_{\mathrm{u}}-\mathrm{a}^{1} \Delta_{\mathrm{g}} \mathrm{V}=0$ transition discussed in the text. The asterisks (*) indicates absorptions due to metastable $\mathrm{N}$ atoms.

Table 13 Constants $(/ \mathrm{cm}-1)$ for the ${ }^{1} \Delta_{\mathrm{u}}-\mathrm{a}^{1} \Delta_{\mathrm{g}} \mathrm{v}=0$ band at $124.4 \mathrm{~nm}$

\begin{tabular}{|l|l|}
\hline Parameter & Value $/ \mathrm{cm}^{-1}$ \\
\hline Origin $^{\mathrm{a}}$ & $88279.233(20)$ \\
\hline$B$ & $1.44871(33)$ \\
\hline
\end{tabular}




\begin{tabular}{|l|l|}
\hline$D \times 10^{5}$ & $1.12(10)$ \\
\hline Width & $0.5^{\mathrm{b}}$ \\
\hline
\end{tabular}

${ }^{\text {a }}$ Relative to the $J=0, \mathrm{v}=0$ level of the $\mathrm{X}^{3} \Sigma_{\mathrm{g}}{ }^{-}$state.

${ }^{\mathrm{b}}$ Estimate

\section{Conclusions}

We have calculated high quality ab initio transition moments for the $3 \mathrm{p} \pi^{1} \Sigma_{\mathrm{u}}{ }^{+}-\mathrm{b}^{1} \Sigma_{\mathrm{g}}{ }^{+}, 4 \mathrm{p} \pi^{1} \Sigma_{\mathrm{u}}{ }^{+}$ $-\mathrm{b}^{1} \Sigma_{\mathrm{g}}{ }^{+}, 3 \mathrm{p} \pi^{1} \Delta_{\mathrm{u}}-\mathrm{a}^{1} \Delta_{\mathrm{g}}$ and $4 \mathrm{p} \pi^{1} \Delta_{\mathrm{u}}-\mathrm{a}^{1} \Delta_{\mathrm{g}}$ transitions in $\mathrm{O}_{2}$, and validated them against experimental high-resolution spectra of DC discharges in pure oxygen. We have also produced refined rotational analyses of these transitions, with good fits to the experimental data, particularly for the $3 \mathrm{p} \pi^{1} \Sigma_{\mathrm{u}}^{+}$and $4 \mathrm{p} \pi^{1} \Sigma_{\mathrm{u}}{ }^{+}$states, which show by far the clearest rotational structure. The cross sections calculated by our model are thus likely to be the most accurate for these bands, as the quality of the model is a strong indicator that we have included all of the important state interactions in our model. These transitions are thus the most promising for determining $\mathrm{b}^{1} \Sigma_{\mathrm{g}}{ }^{+}$number densities, and of these the most practical is likely to be the 1-0 band of the $4 \mathrm{p} \pi^{1} \Sigma_{\mathrm{u}}{ }^{+}-\mathrm{b}^{1} \Sigma_{\mathrm{g}}{ }^{+}$transition, as it is the least affected by the $\mathrm{O}_{2}$ ground-state continuum. The results are likely to be most accurate if the instrumental technique used can resolve the rotational transitions.

The determination of absolute $b^{1} \Sigma_{\mathrm{g}}{ }^{+}$number densities through absorption bands where the rotational structure is not resolved is likely to produce less accurate results, because it is not possible to have the same degree of confidence in the model for the rotational structure, which will limit the accuracy to which the overall profile and temperature dependence can be calculated. Development of a more complete model would probably require considering many states simultaneously, including some valence states, and would require significant extension of the ab initio calculations, which are already rather challenging.

\section{Acknowledgements}

This research was performed within the LABEX Plas@par project, and received financial state aid managed by the Agence Nationale de la Recherche, as part of the programme "Investissements d'avenir" under the reference ANR-11-IDEX-0004-02.

\section{Declaration of interest statement}

No potential conflict of interest was reported by the authors.

\section{References}

[1] A. Midey, I. Dotan, S. Lee, W. T. Rawlins, M. A. Johnson, and A. A. Viggiano, Journal of Physical Chemistry A 111, 5218 (2007).

[2] A. Midey, I. Dotan, and A. A. Viggiano, Journal of Physical Chemistry A 112, 3040 (2008).

[3] S. G. Belostotsky, D. J. Economou, D. V. Lopaev, and T. V. Rakhimova, Plasma Sources Science and Technology 14, 532 (2005). 10.1088/0963-0252/14/3/016.

[4] J. T. Gudmundsson, A. M. Marakhtanov, K. K. Patel, V. P. Gopinath, and M. A. Lieberman, Journal of Physics D-Applied Physics 33, 3010 (2000).

[5] J. T. Gudmundsson, A. M. Marakhtanov, K. K. Patel, V. P. Gopinath, and M. A. Lieberman, Journal of Physics D-Applied Physics 33, 1323 (2000).

[6] J. T. Gudmundsson, I. G. Kouznetsov, K. K. Patel, and M. A. Lieberman, Journal of Physics DApplied Physics 34, 1100 (2001).

[7] A. Greb, A. R. Gibson, K. Niemi, D. O'Connell, and T. Gans, Plasma Sources Sci. Technol. 24, 044003 (2015). 10.1088/0963-0252/24/4/044003.

[8] A. Greb, K. Niemi, D. O'Connell, and T. Gans, Applied Physics Letters 103, 244101 (2013). 10.1063/1.4841675. 
[9] F. D. Findlay and D. R. Snelling, The Journal of Chemical Physics 54, 2750 (1971). 10.1063/1.1675240.

[10] J. A. Davidson, C. M. Sadowski, H. I. Schiff, G. E. Streit, Carleton J. Howard, D. A. Jennings, and A. L. Schmeltekopf, The Journal of Chemical Physics 64, 57 (1976). 10.1063/1.431910.

[11] L. C. Lee and T. G. Slanger, The Journal of Chemical Physics 69, 4053 (1978). 10.1063/1.437136.

[12] G. E. Streit, Carleton J. Howard, A. L. Schmeltekopf, J. A. Davidson, and H. I. Schiff, The Journal of Chemical Physics 65, 4761 (1976). 10.1063/1.432930.

[13] T. G. Slanger and G. Black, The Journal of Chemical Physics 70, 3434 (1979). 10.1063/1.437877.

[14] J. T. Gudmundsson, Journal of Physics D-Applied Physics 37, 2073 (2004). Doi 10.1088/00223727/37/15/005.

[15] D. A. Toneli, R. S. Pessoa, M. Roberto, and J. T. Gudmundsson, Journal of Physics D-Applied Physics 48 (2015). 10.1088/0022-3727/48/49/495203.

[16] D. A. Toneli, R. S. Pessoa, M. Roberto, and J. T. Gudmundsson, Journal of Physics D-Applied Physics 48 (2015). 10.1088/0022-3727/48/32/325202.

[17] S. M. Zyryanov and D. V. Lopaev, Plasma Phys Rep+ 33, 510 (2007).

[18] K. Yoshino, W. H. Parkinson, K. Ito, and T. Matsui, J. Mol. Spectrosc. 229, 238 (2005). http://dx.doi.org/10.1016/i.jms.2004.08.020.

[19] D. H. Katayama, S. Ogawa, M. Ogawa, and Y. Tanaka, The Journal of Chemical Physics 67, 2132 (1977). 10.1063/1.435099.

[20] F. Alberti, R. A. Ashby, and A. E. Douglas, Can. J. Phys. 46, 337 (1968). 10.1139/p68-050.

[21] M. Ogawa and K. R. Yamawaki, Can. J. Phys. 47, 1805 (1969). 10.1139/p69-228.

[22] A. Marica Sjödin, Trevor Ridley, Kenneth P. Lawley, and Robert J. Donovan, The Journal of Chemical Physics 118, 8791 (2003). 10.1063/1.1566949.

[23] B. R. Lewis, S. T. Gibson, Aurea A. Tucay, Robert Robertson, Eunsook S. Hwang, Aaron Bergman, and Richard A. Copeland, The Journal of Chemical Physics 114, 8364 (2001). 10.1063/1.1367333.

[24] Kanzo Robert Yamawaki, USC, 1972.

[25] R. J. Collins, D. Husain, and R. J. Donovan, Journal of the Chemical Society, Faraday Transactions 2: Molecular and Chemical Physics 69, 145 (1973). 10.1039/F29736900145.

[26] J. P. England, B. R. Lewis, and M. L. Ginter, The Journal of Chemical Physics 103, 1727 (1995). 10.1063/1.469746.

[27] S. Yu, B. J. Drouin, and C. E. Miller, J Chem Phys 141, 174302 (2014). 10.1063/1.4900510.

[28] S. Ogawa and M. Ogawa, Can. J. Phys. 53, 1845 (1975). 10.1139/p75-236.

[29] James S. A. Brooke, Peter F. Bernath, Colin M. Western, Christopher Sneden, Melike Afşar, Gang Li, and louli E. Gordon, J. Quant. Spectrosc. Radiat. Transf. (2015). http://dx.doi.org/10.1016/j.jqsrt.2015.07.021.

[30] Nelson de Oliveira, Mourad Roudjane, Denis Joyeux, Daniel Phalippou, Jean-Claude Rodier, and Laurent Nahon, Nature Photonics 5, 149 (2011). 10.1038/nphoton.2010.314.

[31] Nelson de Oliveira, Denis Joyeux, Mourad Roudjane, Jean-Francois Gil, Bertrand Pilette, Lucy Archer, Kenji Ito, and Laurent Nahon, Journal of Synchrotron Radiation 23, 887 (2016). doi:10.1107/S1600577516006135.

[32] M. L. Niu, E. J. Salumbides, A. N. Heays, N. de Oliveira, R. W. Field, and W. Ubachs, Mol. Phys. 114, 627 (2016). 10.1080/00268976.2015.1108472.

[33] M. L. Niu, E. J. Salumbides, D. Zhao, N. de Oliveira, D. Joyeux, L. Nahon, R. W. Field, and W. Ubachs, Mol. Phys. 111, 2163 (2013). 10.1080/00268976.2013.793889.

[34] Hans-Joachim Werner, Peter J. Knowles, Gerald Knizia, Frederick R. Manby, and Martin Schütz, Wiley Interdisciplinary Reviews: Computational Molecular Science 2, 242 (2012). 10.1002/wcms.82.

[35] H.-J. Werner, P. J. Knowles, G. Knizia, F. R. Manby, M. Schütz, P. Celani, W. Györffy, T. Korona, R. Lindh, A. Mitrushenkov, G. Rauhut, K. R. Shamasundar, T. B. Adler, R. D. Amos, A. Bernhardsson, A. Berning, D. L. Cooper, M. J. O. Deegan, A. J. Dobbyn, F. Eckert, E. Goll, C. Hampel, A. Hesselmann, G. Hetzer, T. Hrenar, G. Jansen, C. Köppl, Y. Liu, A. W. Lloyd, R. A. Mata, A. J. May, S. 
J. McNicholas, W. Meyer, M. E. Mura, A. Nicklass, D. P. O'Neill, P. Palmieri, K. Pflüger, R. Pitzer, M. Reiher, T. Shiozaki, H. Stoll, A. J. Stone, R. Tarroni, T. Thorsteinsson, M. Wang, and A. Wolf, (2015) pp. MOLPRO.

[36] David E. Woon and Thom H. Dunning, The Journal of Chemical Physics 100, 2975 (1994). 10.1063/1.466439.

[37] Karen L. Schuchardt, Brett T. Didier, Todd Elsethagen, Lisong Sun, Vidhya Gurumoorthi, Jared Chase, Jun Li, and Theresa L. Windus, Journal of Chemical Information and Modeling 47, 1045 (2007). 10.1021/ci600510j.

[38] Hans-Joachim Werner and Peter J. Knowles, The Journal of Chemical Physics 82, 5053 (1985). 10.1063/1.448627.

[39] Peter J. Knowles and Hans-Joachim Werner, Chemical Physics Letters 115, 259 (1985). http://dx.doi.org/10.1016/0009-2614(85)80025-7.

[40] Hans-Joachim Werner and Peter J. Knowles, The Journal of Chemical Physics 89, 5803 (1988). 10.1063/1.455556.

[41] Peter J. Knowles and Hans-Joachim Werner, Chemical Physics Letters 145, 514 (1988). http://dx.doi.org/10.1016/0009-2614(88)87412-8.

[42] Robert J. Le Roy, Journal of Quantitative Spectroscopy and Radiative Transfer 186, 167 (2017). http://dx.doi.org/10.1016/j.jqsrt.2016.05.028.

[43] R. Ogorzalek Loo, W. J. Marinelli, P. L. Houston, S. Arepalli, J. R. Wiesenfeld, and R. W. Field, The Journal of Chemical Physics 91, 5185 (1989). 10.1063/1.457589.

[44] B. R. Lewis, S. T. Gibson, S. S. Banerjee, and H. Lefebvre-Brion, The Journal of Chemical Physics 113, 2214 (2000). 10.1063/1.482035.

[45] James K. G. Watson, J. Mol. Spectrosc. 125, 428 (1987). https://doi.org/10.1016/00222852(87)90108-1.

[46] Colin M. Western, Journal of Quantitative Spectroscopy and Radiative Transfer 186, 221 (2017). http://dx.doi.org/10.1016/j.jqsrt.2016.04.010.

[47] A Chatterjee, JP Booth, O Guaitella, D Lopaev, S Zyryanov, N de Oliveira, and L Nahon.

[48] R. W. Field, B. G. Wicke, J. D. Simmons, and S. G. Tilford, J. Mol. Spectrosc. 44, 383 (1972). https://doi.org/10.1016/0022-2852(72)90111-7.

[49] B. R. Lewis, J. P. England, R. J. Winkel, S. S. Banerjee, P. M. Dooley, S. T. Gibson, and K. G. H. Baldwin, Physical Review A 52, 2717 (1995). 10.1103/PhysRevA.52.2717.

[50] B. R. Lewis, S. T. Gibson, M. Emami, and J. H. Carver, Journal of Quantitative Spectroscopy and Radiative Transfer 40, 1 (1988). http://dx.doi.org/10.1016/0022-4073(88)90025-8. 